San Jose State University

SJSU ScholarWorks

Master's Theses

Master's Theses and Graduate Research

1996

\title{
The development of two new stationary phases for hydrophobic interaction chromatography
}

Robert M. Mavar

San Jose State University

Follow this and additional works at: https://scholarworks.sjsu.edu/etd_theses

\section{Recommended Citation}

Mavar, Robert M., "The development of two new stationary phases for hydrophobic interaction

chromatography" (1996). Master's Theses. 1392.

DOI: https://doi.org/10.31979/etd.anky-n9vh

https://scholarworks.sjsu.edu/etd_theses/1392

This Thesis is brought to you for free and open access by the Master's Theses and Graduate Research at SJSU ScholarWorks. It has been accepted for inclusion in Master's Theses by an authorized administrator of SJSU

ScholarWorks. For more information, please contact scholarworks@sjsu.edu. 


\section{INFORMATION TO USERS}

This manuscript has been reproduced from the microfilm master. UMI films the text directly from the original or copy submitted. Thus, some thesis and dissertation copies are in typewriter face, while others may be from any type of computer printer.

The quality of this reproduction is dependent upon the quality of the copy submitted. Broken or indistinct print, colored or poor quality illustrations and photographs, print bleedthrough, substandard margins, and improper alignment can adversely affect reproduction.

In the unlikely event that the author did not send UMI a complete manuscript and there are missing pages, these will be noted. Also, if unauthorized copyright material had to be removed, a note will indicate the deletion.

Oversize materials (e.g., maps, drawings, charts) are reproduced by sectioning the original, beginning at the upper left-hand comer and continuing from left to right in equal sections with small overlaps. Each original is also photographed in one exposure and is included in reduced form at the back of the book.

Photographs included in the original manuscript have been reproduced xerographically in this copy. Higher quality 6" $\times$ 9" black and white photographic prints are available for any photographs or illustrations appearing in this copy for an additional charge. Contact UMI directly to order.

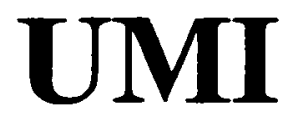

A Bell \& Howell Information Company 300 North Zeeb Road, Ann Arbor MI 48106-1346 USA 
THE DEVELOPMENT OF TWO NEW STATIONARY PHASES

FOR HYDROPHOBIC INTERACTION CHROMATOGRAPHY

\author{
A Thesis \\ Presented to \\ The Facuity of the Department of Chemistry \\ San Jose State University
}

In Partial Fullfillment

of the Requirements for the Degree

Master of Science

By

Robert M. Mavar

December 1996 
UMI Number: 1382596

\section{UMI Microform 1382596}

Copyright 1997, by UMI Company. All rights reserved.

This microform edition is protected against unauthorized copying under Title 17, United States Code.

\section{UMI \\ 300 North Zeeb Road \\ Ann Arbor, MI 48103}


APPROVED FOR THE DEPARTMENT OF CHEMIISTRY
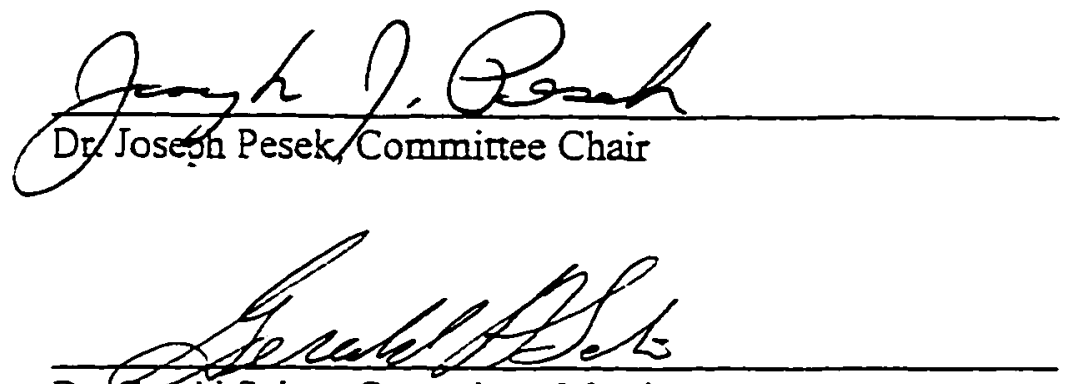

Dr. Eerald Selter, Committee Member

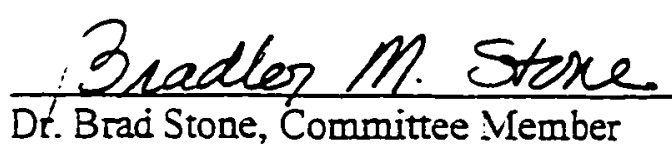

APPROVED FOR THE UNTVERSITY

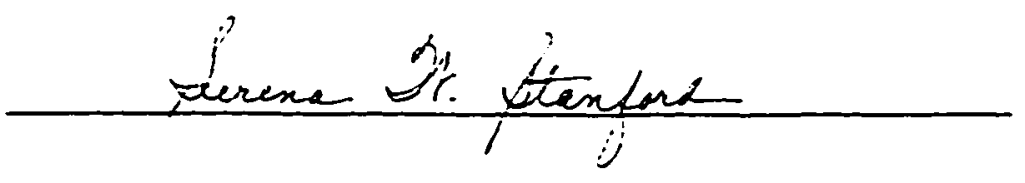


() 1996

Robert M. Mavar

ALL RIGHTS RESERVED 


\section{ABSTRACT \\ THE DEVELOPMENT OF TWO NEW STATIONARY PHASES FOR HYDROPHOBIC INTERACTION CHROMATOGRAPHY}

\section{by Robert M. Mavar}

High performance hydrophobic interaction chromatography (HIC) has developed into an important technique for the separation of proteins and other biomolecules. Two new stationary phases, butylhydroxy and butylphenyl, for hydrophobic interaction chromatography were prepared by reacting a terminal olefin with silica hydride in the presence of a platinum catalyst. A reversed-phase (RPLC) octyl stationary phase was prepared in the same manner for use as a reference material.

The three stationary phases were characterized by chromatographic and nonchromatographic techniques in order to determine their respective degrees of hydrophobicity and polar selectivity as well as to elucidate their structures. Based on chromatographic data, the butylhydroxy column shows hydrophobic interaction character, while the butylphenyl stationary phase shows reversed-phase character as does the octyl reversed-phase reference material. 


\section{ACKNOWLEDGEMENTS}

I would like to express my sincere thanks to my research advisor, Dr. Joseph Pesek, for his guidance and patience throughout my research. I would also like to thank Dr. Maria Matyska and Mr. Bartolemiej Sluzarski for their assistance in my research work.

I would like to acknowledge the members of my thesis committee, Dr. Gerald Selter and Dr. Brad Stone.

I would also like to thank my employers at SRI Intemational, Mr. Andrew Cheung and Dr. Peter Lim for financial aid and the use of their facilities and equipment.

Finally, I would like to thank my family for their support. encouragement and motivation throughout my studies. 


\section{TABLE OF CONTENTS}

ACKNOWLEDGEMENTS

TABLE OF CONTENTS vi

LIST OF TABLES vii

LIST OF FIGURES viii

1. INTRODUCTION

1.1. Background 1

1.2. Aims of This Work 6

2. EXPERIMENTAL

2.1. Materials

2.2. Instrumentation 8

2.3. Synthetic Procedures 9

2.3.1. Synthesis of Silica Hydride 9

2.3.2. Synthesis of Butylhydroxy, Butylphenyl and Octyl Stationary Phases 9

2.4. High Performance Liquid Chromatography 11

2.4.1. Chromatographic System 11

2.4.2. Test Components 11

2.4.3. Conditions 11

3. RESULTS AND DISCUSSION 12

3.1. Spectroscopic and Elemental Analyses 12

3.1.1. Diffuse Reflectance Infrared Fourier
Transform (DRIFT)

3.1.2. ${ }^{13} \mathrm{C}$ Nuclear Magnetic Resonance $\left({ }^{13} \mathrm{C}-\mathrm{NMR}\right)$

3.1.3. Elemental Analysis 14

3.2. Chromatographic Analysis 15

4. CONCLUSION 24

$\begin{array}{ll}\text { REFERENCES } & 26\end{array}$

$\begin{array}{ll}\text { APPENDIX A (Tables) } & 27\end{array}$

APPENDIX B (Figures) 


\section{LIST OF TABLES}

Table I. Comparison of RPLC and HIC

Table II. Surface Coverage

29

Table III. Hydrophobicity and Polar Selectivity Data

30

Table IV. Protein Retention Data

31 


\section{LIST OF FIGURES}

Figure 1. Sample chromatograms of environmental, biological and pharmaceutical samples separated by reversed-phase liquid chromatography

Figure 2. Chromatography modes and their applications

Figure 3. HPLC silica bonded reversed-phases chromatography

Figure 4. Chromatographic system

Figure 5. Series of homologues used to characterize stationary phases

Figure 6. DRIFT spectrum of silica intermediate

Figure 7. DRIFT spectrum of octyl bonded phase

Figure 8. Expanded DRIFT spectrum $\left(3200-2700 \mathrm{~cm}^{-1}\right)$ of octyl bonded phase

Figure 9. DRIFT spectrum of butylhydroxy bonded phase

Figure 10. Expanded DRIFT spectrum $\left(3200-2700 \mathrm{~cm}^{-1}\right)$ of butylhydroxy bonded phase

Figure 11. DRIFT spectrum of butylphenyl bonded phase

Figure 12. Expanded DRIFT spectrum $\left(3200-2700 \mathrm{~cm}^{-1}\right)$ of butylphenyl bonded phase

Figure 13. ${ }^{13} \mathrm{C}-\mathrm{NM} R$ (CP-MLAS) spectrum of octyl bonded phase

Figure $14 .{ }^{13} \mathrm{C}-\mathrm{NM} R$ (CP-iMAS) spectrum of butylphenyl bonded phase

Figure $15 .{ }^{13} \mathrm{C}-\mathrm{N} M \mathrm{MR}$ (CP-iMAS) spectrum of butylhydroxy bonded phase

Figure 16. Measurements used to calculate theoretical plate count 


\section{LIST OF FIGURES (cont'd)}

Figure 17. Measurements used to calculate capacity factor 49

Figure 18. Measurements used to calculate resolution 50

Figure 19. Measurements used to calculate relative retention 51

Figure 20. HPLC chromatogram of paraben mixture on butylhydroxy column

Figure 21. HPLC chromatogram of benzene mixture on butylhydroxy column

Figure 22. HPLC chromatogram of dialkyl phthalate mixture on butylhydroxy column

Figure 23. HPLC chromatogram of paraben mixture on butylphenyl column

Figure 24. HPLC chromatogram of benzene mixture on butylphenyl column

Figure 25. HPLC chromatogram of dialkyl phthalate mixture on butylphenyl column

Figure 26. HPLC chromatogram of paraben mixture on octyl column

Figure 27. HPLC chromatogram of benzene mixture on octyl column

Figure 28. HPLC chromatogram of dialkyl phthalate mixture on octyl column

Figure 29. HPLC chromatogram of bovine serum albumin on butylhydroxy column

Figure 30. HPLC chromatogram of cytochrome $\mathrm{C}$ on butylhydroxy column 


\section{LIST OF FIGURES (cont'd)}

Figure 31. HPLC chromatogram of ribonuclease $A$ on butylhydroxy column

Figure 32. HPLC chromatogram of bovine serum albumin on butylphenyl column

Figure 33. HPLC chromatogram of cytochrome $\mathrm{C}$ on butylphenyl column

Figure 34. HPLC chromatogram of ribonuclease $\mathrm{A}$ on butylphenyl column

Figure 35. HPLC chromatogram of bovine serum albumin on octyl column

Figure 36. HPLC chromatogram of cytochrome $\mathrm{C}$ on octyl column

Figure 37. HPLC chromatogram of ribonuclease $A$ on octyl column 


\section{INTRODUCTION}

\subsection{Background}

High performance liquid chromatography has a wide variety of applications for the separation of many types of compounds, including environmental, biological and pharmaceutical samples (Figure 1). Development of new stationary phases as well as improvements in existing types are aimed at creating packings for specific separations and increasing the performance of the columns.

There are four traditional separation modes in liquid chromatography: (1) partition, (2) adsorption, (3) size exclusion and (4) ion exchange (Figure 2).

Partition chromatography involves the partitioning of a solute between a liquid stationary phase and a liquid mobile phase. The stationary phase is bonded onto an inert solid support and packed into a column. The separation of components in a sample is due to the differences in solubilties of the sample components in the two phases. The liquid stationary phase and the liquid mobile phase must be immiscible. Therefore, the polarity of the stationary phase is opposite that of the mobile phase.

Within the partition phase mode, there are two "sub-modes" of separation. The first, normal phase, uses a polar stationary phase and a non-polar mobile phase. The other, reversed-phase, uses a non-polar stationary phase with a polar mobile phase. The second, reversed-phase, has become the most widely used of all the liquid chromatographic separation modes. The selectivity in reversed-phase chromatography is often different than that in normal phase chromatography. The elution order in the 
reversed-phase can be related to the increasing hydrophobic nature of the solute. This means that solutes which are more water-soluble will be eluted faster. The development and widespread use of reversed-phase liquid chromatography can be attributed, in part, to the fact that this hydrophobic effect provides a selectivity not available to separation modes based exclusively on size or charge.

Adsorption chromatography involves the adsorption of solutes onto polar adsorbents such as silica gel or alumina. Also called liquid-solid chromatography, it is the oldest form of the four types of chromatographic modes. In 1903, Tswett, who is generally credited with the discovery of chromatography, used the technique which is now referred to as adsorption chromatography, to separate pigments in green leaves. The adsorption mechanism can be best described as the establishment of an equilibrium inside a column. A mobile phase having a polarity similar to that of a sample is pumped through the column. The sample, which has been adsorbed onto the stationary phase is dislogded. As the sample is flushed through the column, it repeatedly adsorbs and is dislodged at available bonding sites along the stationary phase.

Ion exchange chromatography separates ionic species with the help of ionexchangers as the stationary phase. These ion-exchange stationary phases carry positive or negative charges. The mobile phase consists of a stoichiometric equivalent of oppositely charged ions. These "counter-ions" are then exchanged onto the stationary phase for sample ions having the same charge. 
Finally, in size exclusion chromatography, components in a sample are separated based on their molecular size. Basically, the stationary phase contains porous particles with different pore diameters. Solutes will diffuse into pores that have diameters greater than that of the solute. As the diameter of the solute increases, the number of pores which it can diffuse into decreases. Larger diameter molecules will, therefore, be eluted faster than smaller diameter molecules.

The most common type of separation mode, as mentioned earlier, is reversedphase liquid chromatography. It has been estimated that approximately $70 \%$ of all liquid chromatographic analyses are carried out in the reversed-phase mode. The ligands on the stationary phase in a typical reversed-phase column are densely distributed, long alkyl chains such as octyl or octadecyl moieties. These ligands produce a very hydrophobic surface. Subsequently, organic solvents must be used to desorb proteins from the column surface. As a result of the use of organic solvents, proteins are prone to unfolding and the loss of biological activity. It is therefore desirable to develop a technique which would not damage the protein or alter its conformation. One alternative technique is hydrophobic interaction chromatography.

In the last decade, high performance hydrophobic interaction chromatography has developed into a powerful technique for the separation of proteins and other biomolecules. The molecular interaction involved, London-type dispersion, is very similar to that in reversed-phase chromatography. There are, however, substantial differences with respect to the separation of biological samples (Table I). As mentioned 
previously, in reversed-phase chromatography, the ligands are densely distributed, long alkyl chains which produce strongly hydrophobic surfaces. There is, therefore, strong interaction between biologically active components and the stationary phase, requiring organic solvents to desorb the solute. Conversely, hydrophobic interaction stationary phases contain short aikyl or cyclic ligands which are more sparsely distributed. This results in surfaces which are only moderately hydrophobic, thereby reducing hydrophobic interaction. Elution of biomolecules, such as proteins, can then be accomplished with the use of aqueous solvents without the addition of organic modifiers.

The majority of reversed-phases have the ligands bonded to the silica solid support through a siloxane bridge (Figure 3). These stationary phases are prepared with chlorodimethylalkyl-silane reagents in the presence of base, as shown below,

$$
\mathrm{Si}-\mathrm{OH} \div \mathrm{Cl}-\mathrm{Si}\left(\mathrm{CH}_{3}\right)_{2}-\mathrm{R} \longrightarrow \mid \mathrm{Si}-\mathrm{O}-\mathrm{Si}\left(\mathrm{CH}_{3}\right)_{2}-\mathrm{R}+\mathrm{HCl}
$$

where the $\mathrm{R}$ group is usually a long alkyl chain.

This method suffers from several drawbacks, namely, the limited organic surface coverage and, more importantly, the lack of hydrolytic stability of the siloxane-carbon linkage. Insufficient surface coverage and hydrolytic instability result in the exposure of surface silanols. Silanols are believed to be responsible for the adsorption phenomena that afflict silica-based stationary phases. These phenomena are especially problematic when dealing with proteins and other biomolecules. For example, biomolecules 
containing amino and similar groups may interact with the unreacted silanols. This strong interaction may lead to ireversible adsorption of the molecule onto the column packing or severe tailing.

The instability of the siloxane-carbon linkage is a major disadvantage in the use of the siloxane bridge for ligand bonding to the solid support. In the separation of proteins, it is often necessary to use low $\mathrm{pH}$ buffers or trifluoroacteic acid. The use of these acidic media leads to harsh conditions which are detrimental to column stability. The low $\mathrm{pH}$ media attack the bonded ligands and lead to loss of bonded material. This, in turn, leads to the increase of silanol groups on the stationary phase surface to which biomolecules strongly bind.

In an attempt to overcome these instability problems, different methods have been used to bond ligands to the solid support. One method involves replacing the methyl groups of the chlorodimethylalkyl-silane reagent with bulkier groups. The idea is to shield, or sterically hinder unreacted silanols from interacting with solutes. There is a marked improvement in reducing the interaction between the silanols and solutes. However, the method still involves formation of the hydrolytically unstable siloxanecarbon bond.

A novel approach, a direct silica-carbon linkage, has been developed to bond the ligands to the solid support. This method involves the hydrosilation of a terminal olefin. This method not only affords a more stable silica-ligand bond, it also increases ligand coverage of the stationary phase. 


\subsection{Aims of This Work}

This research has two primary objectives. The first is to synthesize two new stationary phases for hydrophobic interaction chromatography. The second is to evaluate these two stationary phases in terms of their physical and chemical properties. These results will then be compared to those of a standard octyl stationary phase which will be synthesized analogously.

The synthetic route involves the hydrosilation of terminal olefins directly onto a silica hydride support in the presence of a platinum catalyst.

$$
\mathrm{Si}-\mathrm{H}+\mathrm{CH}_{2}=\mathrm{CH}-\mathrm{R} \longrightarrow \mid \mathrm{Si}-\mathrm{CH}_{2} \mathrm{CH}_{2}-\mathrm{R}
$$

This reaction should result in an anti-Markovnikov addition at the silica surface.

The second objective, the evaluation of the new stationay phases, will be achieved by both chromatographic and non-chromatographic techniques. Chromatographic techniques will be used to determine chemical parameters such as the hydrophobicity and polar character of the stationary phases. Specifically, three series of homologues, as well as several proteins, will be chromatographed on each of the three stationary phases. From the retention behavior of the solutes and regression analyses, the aforementioned chemical parameters will be determined. Non-chromatographic techniques, elemental analysis and infrared and nuclear magnetic resonance spectroscopies, will be used to 
elucidate the structures and determine physical properties such as the surface coverage of the stationary phases.

\section{EXPERIMENTAL}

\subsection{Materials}

All chemicals used in the syntheses were of reagent grade. Diethyl ether $(99.9 \%$, Mallinckrodt Chemical, Inc., Paris, KY), isopropanol (99.9\%, Mallinckrodt Chemical, Inc.), methylene chloride ( $99.9 \%$, Mallinckrodt Chemical, Inc.) and toluene ( $299.8 \%$, Fisher Scientific Co., Fair Lawn, NJ) were used as received. A $5 \mathrm{mM}$ hexachloroplatinic acid (37.5\% as Pt, Aldrich Chemical Co., Inc., Milwaukee, WT) solution in 2-propanol was used as a catalyst for hydrosilation. 1-Octene ( $98 \%$, Aldrich Chemical Co., Inc.), 3buten-1-ol (99\%, Aldrich Chemical Co., Inc.) and 4-phenyl-1-butene (99\%, Aldrich Chemical Co., Inc.) were also used as received. Silica (Separations Group, Hesperia, CA) obtained for the preparation of silica hydride was used as received. All glassware was dried at $110^{\circ} \mathrm{C}$ for 24 hours prior to use.

All solvents for high performance liquid chromatography were HPLC grade. Methanol (99.9\%, Mallinckrodt Chemical, Inc.), acetonitrile (99.9\%, Mallinckrodt Chemical, Inc.) and trifluoroacetic acid (>99.9\%, Aldrich Chemical Co., Inc.) were used as received. Milli-Q water was obtained from a Super Q Water Filtration system (Millipore Corp.. Milford. $\mathrm{WLA}$ ) and filtered again through a $0.45 \mu \mathrm{m}$ nylon membrane prior to use. 
Test components for the column characterizations were of reagent grade. The alkyl-p-hydroxybenzoates (99\%. Aldrich Chemical Co., Inc.), dialkyl phthalates (99\%, Aldrich Chemical Co., Inc.) and benzene homologues (>98\%, Aldrich Chemical Co., Inc., Fisher Scientific Co. and :Monsanto Chemicals. Inc., St. Louis, MO) were diluted to $-1 \mathrm{mg} / \mathrm{mL}$ in either methanol or water prior to injection. Bovine serum albumin, cytochrome $c$ and ribonuclease A (Sigma Chemical Co., St. Louis, MO) were diluted in water prior to injection.

\subsection{Instrumentation}

Solid state nuclear magnetic resonance spectra, cross-polarization with magic angle spinning (CP-MLAS), were obtained on a Bruker MSL 300 spectrophotometer. Samples in a $\mathrm{ZrO}_{2}$ rotor were measured at a spinning rate of $5 \mathrm{kHz}$, with a contact time of $3 \mathrm{msec}$ and a repitition rate of $5 \mathrm{sec}$. Tetramethylsilane was used to reference the chemical shifts. Diffuse Reflectance Infrared Fourier Transform spectra were performed on a Perkin-Elmer Model 1800 FTIR spectrometer. Spectra were obtained in the 4000$450 \mathrm{~cm}^{-1}$ region with a resolution of $2 \mathrm{~cm}^{-1}$. Potassium bromide was used as the reference. Elemental analyses were performed by Desert Analytics (Tucson, AZ). A Waters (Waters Corp., Milford, MAA) fully automated high performance liquid chromatography system was used to obtain chromatographic results. The chromatograph consisted of a Model 600 multisolvent delivery system, a 712 WISP autosampler with 20 $\mu \mathrm{L}$ loop and Lambda-Max variable wavelength $\mathrm{UV}$-Vis detector operated at $254 \mathrm{~nm}$ 
(Figure 4). Data was acquired and evaluated on a Waters Maxima data station running on an IBM PC compatible computer. Regression analyses were performed using Microsoft Excel 5.0 software.

\subsection{Synthetic Procedures}

\subsubsection{Synthesis of Silica Hydride}

Five g of silica (Vydac) was reacted with $45 \mathrm{~mL}$ of a $0.5 \mathrm{M}$ triethoxysilane solution (in dioxane) in the presence of water, $7 \mathrm{~mL}$ of $2.3 \mathrm{M}$ hydrochloric acid and 100 $\mathrm{mL}$ dioxane. This yielded a silica hydride monolayer covalently bonded to the silica surface.

$$
\left|\mathrm{Si}-\mathrm{OH}+\mathrm{H}-\mathrm{Si}\left(\mathrm{OCH}_{2} \mathrm{CH}_{3}\right)_{3} \longrightarrow\right| \mathrm{Si}-\mathrm{H}+\mathrm{HO}-\mathrm{Si}\left(\mathrm{OCH}_{2} \mathrm{CH}_{3}\right)_{3}
$$

The resulting product was then washed with two $50 \mathrm{~mL}$ aliquots of 20/80 wateritetrahydrofuran, two $50 \mathrm{~mL}$ aliquots of tetrahydrofuran and two $50 \mathrm{~mL}$ aliquots of diethyl ether. The final product was then dried at room temperarure and then at $110^{\circ} \mathrm{C}$ for a minimum of 6 hours.

\subsubsection{Syntheseis of Butylhydroxy, Butylphenyl and Octyl Stationary Phases}

Each of the three stationary phases was prepared identically. To a three-neck. 250 $\mathrm{mL}$ round bottom flask equipped with an addition funnel, reflux condenser, thermometer, 
heating mantle and magnetic stirrer, a portion of the alkene ( $4.8 \mathrm{~mL}$ of 3 -buten-1-ol; , 9.9 $\mathrm{mL}$ of 4-phenyl-1-butene; and $10.6 \mathrm{~mL}$ of (-octene) in $112 \mathrm{~mL}$ of toluene was added. The mixture was heated to approximately $60^{\circ} \mathrm{C}$, at which time $2.5 \mathrm{~mL}$ of $5 \mathrm{mM}$ hexachloroplatinic acid in 2-propanol was added. This mixture was heated at $60-70^{\circ} \mathrm{C}$ with stirring for 1 hour. After one hour of heating, 2.5 $\mathrm{g}$ of solid silica hydride was added. The temperature was increased to $100 \pm 2{ }^{\circ} \mathrm{C}$ and the mixture heated for an additional 96 hours at constant temperature, after which a gray colored solution resulted.

$$
\left|\mathrm{Si}-\mathrm{H} \div \mathrm{CH}_{2}=\mathrm{CH}-\mathrm{R} \longrightarrow\right| \mathrm{Si}-\mathrm{CH}_{2} \mathrm{CH}_{2}-\mathrm{R}
$$

where $\mathrm{R}=-\mathrm{CH}_{2} \mathrm{CH}_{2} \mathrm{OH}$ for the butylhydroxy ligand synthesis

$$
\begin{aligned}
& \mathrm{R}=-\mathrm{CH}_{2} \mathrm{CH}_{2} \\
& \mathrm{R}=-\left(\mathrm{CH}_{2}\right)_{5} \mathrm{CH}_{3} \text { for the octyl ligand synthesis }
\end{aligned}
$$

The solution was transferred into three separate centrifuge tubes, mixed, centrifuged and the supernatant removed. The solid product was then washed successively with three $30 \mathrm{~mL}$ aliquots of toluene, three $30 \mathrm{~mL}$ aliquots of methylene chloride and three $30 \mathrm{~mL}$ aliquots of diethyl ether. Each washing was followed by approximately 5 minutes of mixing and centrifugation. The supernatant was removed and discarded after each of the first two series of solvents. After the final washing, the 
diethyl ether residue was left to evaporate overnight at room temperature. The final product was then dried at $110^{\circ} \mathrm{C}$ for 12 hours.

\subsection{High Performance Liquid Chromatography}

\subsubsection{Chromatographic System}

A Waters (Waters Corp., Milford, MAA) fully automated high performance liquid chromatograph was used to characterize the stationary phases.

\subsubsection{Test Components}

The test components used to characterize the stationary phases consisted of three sets of homologous series. These series are (1) alkyl-p-hydroxybenzoates (parabens): methyl, ethyl, propyl and butyl; (2) dialkyl phthalates: methyl, ethyl, propyl and butyl; and benzene homologues: benzene, toluene and $m$-xylene (Figure 5). In addition, several proteins were chromatographed to aid in the characterization of the columns. These are bovine serum albumin, cytochrome $\mathrm{c}$ and ribonuclease $\mathrm{A}$.

\subsubsection{Conditions}

Chromatograms of the test components were obtained under isocratic conditions with methanol-water mixtures at a flow rate of $1.0 \mathrm{~mL} / \mathrm{min}$. The mobile phase composition was varied so as to obtain reasonable retention times for all of the components. 
The elution of the proteins was achieved using a linear gradient with an acetonitile ( $0.2 \%$ TFA)-water $(0.2 \%$ TFA) mixture. The gradient was programmed as follows:

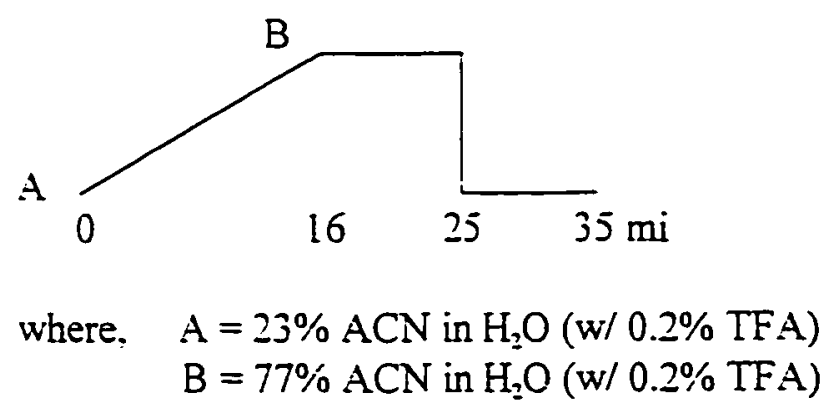

\section{RESULTS AND DISCLSSION}

3.1. Spectroscopic and Elemental Analyses

\subsubsection{Diffuse Reflectance Infrared Fourier Transform}

The DRIFT spectra are shown in Figures 6-12. The silica hydride spectrum (Figure 6) shows a Si-H stretch at $2250 \mathrm{~cm}^{-1}$. Decrease of this band will be one indication of bonding of the ligand to the silica surface. The DRIFT spectra of all three phases, octyl, butylhydroxy and butylphenyl (Figures 7-12), shows the appearance of bands in the $2800-3000 \mathrm{~cm}^{-1}$ region, C-H stretchings of the aliphatic chain, along with a concomitant decrease of the Si-H band. This confirms bonding of each of the ligands to the silica support. 


\subsubsection{Nuclear Magnetic Resonance}

The ${ }^{13} \mathrm{C}-\mathrm{NMMR}$ spectra of the octyl stationary phase (Figure 13 ) shows five signals. The signal at 12.7 ppm can be assigned to the C-1 and C-8 methylenes, the signal at 22.4 ppm is assigned to the C-2 and C-7 methylenes, $29.1 \mathrm{ppm}$ is the $\mathrm{C}-4$ and $\mathrm{C}-5$ methylenes signal and $31.9 \mathrm{ppm}$ is from the $\mathrm{C}-3$ and C -6 methylenes. The extraneous singlet at 17.0 ppm, which is found in all three stationary phase spectra, is due to the methyl moiety from triethoxysilane used in the preparation of the silica hydride intermediate.

The ${ }^{15} \mathrm{C}-\mathrm{NM}$ R spectra of the butylphenyl stationary phase (Figure 14) shows seven signals and they are assigned as follows. The C-1 and C-2 methylenes are assigned to the 12.1 and 22.8 ppm signals, the $C-3$ and $C-4$ methylenes are at 34.6 and $66.2 \mathrm{ppm}$. and finally the phenyl carbons are assigned to the intense signal at $127.8 \mathrm{ppm}$. Again, the 16.7 ppm peak is the triethoxysilane methyl and the 60.4 ppm signal is the ethoxy group of the same material.

The ${ }^{15} \mathrm{C}-\mathrm{N} M$ RR spectra of the butylhydroxy stationary phase (Figure 15) shows more signals than expected. Once again, the triethoxysilane methyl and ethoxy signals are present at 16.6 and $61.1 \mathrm{ppm}$, respectively. The $\mathrm{C}-1$ and $\mathrm{C}-2$ methylenes are assigned to the 12.6 and 22.0 ppm signals. The $C-3$ methylene is at 36.2 ppm, while the $C-4$ methylene is buried under the ethoxy signal in the $55-70 \mathrm{ppm}$ region. In addition to the expected signals, this spectrum shows additional signals in the $110-140$ ppm region. These signals can be attributed to bonding of the olefin to the silica support through the 
hydroxyl group of the butylhydroxy molecule rather than through the terminal methylene group. The signals are, therefore, due to the olefinic carbons as well as their neighbors.

\subsubsection{Elemental Analysis}

Elemental analysis provides important information regarding the surface coverage of the ligands on the solid support. Elemental analysis showed the butylhydroxy phase to contain $2.87 \%$ carbon, the butylphenyl phase $4.25 \%$ carbon and the octyl phase $3.18 \%$ carbon. The surface coverage is calculated using the Sander-Wise Equation (below) which uses carbon content (expressed as percent), the number of carbon atoms in the ligand, the molecular weight of the ligand and the surface area of the silica solid support. A correction is made to compensate for the carbon which was present in the silica hydride intermediate, due to unreacted triethoxysilane, before bonding (determined to be $0.7 \%$ ). The corrected values are, therefore, $2.17 \%$ carbon for the butylhydroxy phase, $3.55 \%$ carbon for the butylphenyl phase and $2.48 \%$ carbon for the octyl phase (Table II).

The surface coverage is expressed as $\mu \mathrm{mol} / \mathrm{m}^{2}$.

$$
\mu \mathrm{mol} / \mathrm{m}^{2}=\frac{\mathrm{P}_{\mathrm{s}} \times 10^{6}}{\mathrm{n}_{\mathrm{c}}(1200)-\mathrm{P}_{\mathrm{c}}(\mathrm{M}-1)} \times \frac{1}{\mathrm{~S}}
$$

$$
\text { where, } \quad \begin{aligned}
& P_{i}=\% C \text { (after correction) } \\
& n_{=}=\text {number of carbon atoms in the ligand } \\
& . \mathrm{II}=\text { molecular weight of the ligand } \\
& \left.\mathrm{S}=\text { surface area of silica (Vydac }=106 \mathrm{~m}^{2} / \mathrm{g}\right)
\end{aligned}
$$

The results show that the butylhydroxy stationary phase has the highest surface coverage at $4.41 \mu \mathrm{mol} / \mathrm{m}^{2}$. The butylphenyl and octyl phases show less surface coverage at 2.90 
and $2.51 \mu \mathrm{mol} / \mathrm{m}^{2}$. When these values are compared to those of commercially available columns, several observations may be made.

First, the octyl phase surface coverage $\left(2.51 \mu \mathrm{mol} / \mathrm{m}^{2}\right)$ is consistent with that of commercially available columns, which have surface coverages ranging from $2.4-3.9$ $\mu \mathrm{mol} / \mathrm{m}^{2}$. The higher coverage is associated with column packings which are described as having "ultra-high" carbon loading, and therefore have higher hydrophibic, or reversed-phase character. The butylphenyl phase surface coverage $\left(2.90 \mu \mathrm{mol} / \mathrm{m}^{2}\right)$ is quite high with respect to commercial phenyl packing materials which have surface coverages ranging from $1.1-2.4 \mu \mathrm{mol} / \mathrm{m}^{2}$. Once again, the higher, or more dense surface coverage may result in a stationary phase which is more hydrophobic, and therefore more reversed phase in nature, than was intended. Finally, the butylhydroxy phase surface coverage $\left(4.41 \mu \mathrm{mol} / \mathrm{m}^{2}\right)$ is relatively bigh when compared to the octyl and butylphenyl phases. The high coverage in this phase may reduce hydrophobic interaction character as well.

\subsection{Chromatographic Analysis}

Retention times of a solute at a specific mobile phase composition, whether on columns with identical or different stationary phases may vary. A major cause for this variation is non-uniform coverage of the solid support. This non-uniform coverage may lead to interaction between solutes and unreacted, or uncovered sites. As an example, many biomolecules interact strongly with unreacted silanols. This strong interaction may 
result in peak tailing, or in some instances, irreversible adsorption of the biomolecule onto the stationary phase. It is therefore necessary to characterize new columns before use. A broad range of chromatographic techniques are available for stationary phase characterization.

Chromatographic characterization applies the information obtained from retention behavior of certain solutes. There are three methods which make use of this type of technique: (1) characterization of efficiency properties, (2) calibration of the stationary phase and (3) characterization of specific properties.

The first, characterization of efficiency properties, mostly reflects the kinetics of the separation. Efficiency properties include theoretical plate number, capacity factor, resolution and relative retention. The theoretical plate number, or plate count, is the assessment of the number of partitioning steps a solute goes through (Figure 16). It is calculated using the following expression,

$$
\mathrm{a}=5.54\left(\mathrm{t}_{\mathrm{R}} / \mathrm{w}_{\mathrm{h}}\right)^{2}
$$

where, $\quad \mathrm{a}=$ number of theoretical plates

$\mathrm{t}_{\mathrm{R}}=$ retention time of peak

$\mathrm{w}_{\mathrm{b}}=$ peak width at half-height

5.54 is a constant

The stationary phases prepared in this work have the following plate numbers calculated from the propyl paraben peak in each phases respective chromatogram: butylhydroxy phase $n=15,200$ plates/meter: butylphenyl phase $n=27,860$ plates $/$ meter; octyl phase $n$ $=25.687$ plates/meter. All three columns show good theoretical plate counts. 
The capacity factor is used to express the ratio of time a solute spends between the stationary phase and the mobile phase (Figure 17), and it is expressed as

$$
k=\left(t_{R}-t_{M}\right) / t_{M}
$$

$$
\text { where, } \quad \begin{aligned}
& k=\text { capacity factor } \\
& t_{R}=\text { retention time of peak of interest } \\
& t_{\mathrm{I}}=\text { retention time of an unretained solute }
\end{aligned}
$$

The butylhydroxy phase has a $k=0.93$, the butylphenyl phase $k=0.95$ and the octyl phase $k=1.08$ for propyl paraben .

Resolution is a measure of the ratio between two peaks, or the actual separation between peaks (Figure 18). It is calculated with the equation

$$
\mathrm{R}_{\mathrm{S}}=\Delta \mathrm{T} / \mathrm{SW} \mathrm{W}_{12}
$$

$$
\begin{array}{ll}
\text { where, } & R_{S}=\text { resolution } \\
& \Delta T=\text { difference in retention times between two peaks } \\
& \Sigma W_{1 \Omega}=\text { sum of mid-widths of two peaks }
\end{array}
$$

Using the propyl paraben and butyl paraben peaks to determine the resolution of each column gives the butylhydroxy phase $R_{S}=4.45$, the butylphenyl phase $R_{S}=4.05$ and the octyl phase $R_{S}=4.51$. These values clearly indicate "baseline resolution" for the two peaks in question. A value of $\geq 1.5$ indicates complete, or "baseline resolution".

Relative retention describes the relative position of two adjacent peaks (Figure 19). This term is used because separation of components is dependent upon selective interaction with the stationary phase. It is the time spent in the separation phase, not the time traveled along the column. The relative retention is calculated using the following equation, 


$$
\alpha=t_{R}^{\prime} / t_{R I}
$$

where, $\quad \alpha=$ resolution

$\mathrm{t}_{\mathrm{R}=}^{\prime} \& \mathrm{t}_{\mathrm{R} 1}^{\prime}=$ retention times of the 2 nd and $1 \mathrm{st}$ peaks, respectively

Again, using the propyl paraben and butyl paraben peaks to calculate the relative retention gives the following values: butylhydroxy phase $\alpha=1.34$; butylphenyl phase $\alpha=$ $1.35 ;$ and octyl phase $\alpha=1.39$.

The second method, calibration of the stationary phase. is used to try to accurately predict retention behavior. A set of components is chromatographed at several mobile phase compositions. An abstract model of retention is built using factor analysis and other multivariate data analysis techniques. Although this method provides adequate results for columns with the same or very similar stationary phases, questionable results are obtained for stationary phases which are different.

The third and final method, the characterization of specific properties, is the primary method which has been used to characterize the stationary phases in this research, and it examines parameters such as hydrophobicity and polar selectivity. Within this method, three "sub-methods" can be used to determine specific properties. (1) Solutes with different molecular properties are chromatographed. The polar-apolar character of the stationary phase is determined from the retention order of the solutes. (2) Homologous series are chromatographed and retention indeces are calculated from their retention behavior. The objective is to obtain "phase-system-independent" parameters. Retention indeces, however. vary with the properties of the stationary phase as well as 
those of the mobile phase. (3) Homologous series are chromatographed over a wide range of mobile phase compositions. Regression analysis is then performed on retention data to obtain hydrophobicity and polar selectivity parameters of the stationary phase.

This research uses the last method, the use of homologous series over a wide range of mobile phase compositions, to evaluate the two new stationary phases. If the same series of solutes are chromatographed on different columns using the same mobile phase, the variations in retention times should reflect the differences in the properties of the stationary phases. In this work, however, such a direct comparison could not be performed due to the fact that differing mobile phases were required to elute the three series of homologues on each of the columns. Figures $20-28$ show the chromatograms of the test mixtures of the various homologues used in this work. As can be seen, the homologues with the shorter chains were retained the least, due to their being the most polar members of their respective series. By cross-comparison of the series on the same column using the same mobile phase shows that the parabens are retained the least, while the dialkyl phthaltes are retained the most. This is as expected since the paraben series is the most polar and the dialkyl phthalate series is the least polar. As previously mentioned, the same mobile phase compositions could not be used throughout. There were, however, some compositions which were identical. An indirect approach. therefore, is required where a correction is made to compensate for mobile phase variation. 
For such a comparison, an extrapolation of the natural log of the capacity factor to $100 \%$ water is utilized. This parameter is not affected by the type of organic modifier used, and water is the modifier that affords the greatest differences in the retention times of the solutes. This measure is calculated using the following equation

$$
\ln k=\ln k_{w}-\mathrm{Sx}
$$

$$
\begin{aligned}
& \text { where, } \quad \begin{array}{l}
\text { In } k=\text { natural log of the capacity factor } \\
\ln k_{w}=\text { intercept (equal to } 100 \% \mathrm{H}_{2} \mathrm{O} \text { ) } \\
\mathrm{S}=\text { slope } \\
\mathrm{x}=\% \mathrm{MeOH} \text { content of mobile phase }
\end{array}
\end{aligned}
$$

The slope and $y$-intercept are obtained from linear regression of the chromatographic profile. Having obtained these values. the hydrophobic selectivity of the stationary phases may be determined.

Hydrophobic selectivity, $\mathrm{m}_{0}$, describes the apolar character of the stationary phases. It is calculated using the following equation

$$
\mathrm{m}_{0}=-\ln k_{w} / \mathrm{S}
$$

$$
\begin{array}{ll}
\text { where, } & \mathrm{m}_{0}=\text { hydrophobic selectivity } \\
\ln k_{w}=\text { intercept for molecular residue } \\
\mathrm{S}=\text { slope }
\end{array}
$$

The molecular residue is the 0 carbon substituted member of the homologous series. This research used the paraben series (n-alkyl-p-hydroxybenzoates), dialkyl phthalate series and benzene homologue series for chromatographic characterization. In the case of the parabens, the molecular residue is $p$-hydroxybenzoate, for the dialkyl phthalates it is $1,2-$ 
benzenedicarboxylic acid and for the benzene homologues the 0 carbon substituted member is benzene itself.

Based on the work of Hetem and co-workers, it was found that the hydrophobicity calculated for the benzene homologues correlated best with the hydrophobicity of the stationary phases. That is, the hydrophobicity increased as the ligand chain length increased. In addition, it was also determined that the polar selectivity calculated for the paraben series showed the best correlation with the uncovered silica surface. It was therefore evident that the hydrophobicity and polarity parameters were dependent upon the test components used in the characterization.

The data in this research show that based on the benzene homologous series, the octyl stationary phase has the greatest hydrophobicity value (Table III). The higher, or in this case least negative value corresponds to greater hydrophobicity. This, in turn, indicates reversed-phase character. This agrees with the predicted outcome, as octyl phases are known to operate in the reversed-phase. Therefore, the octyl column has the greatest hydrophobicity, followed by the butylphenyl phase, and finally the butylhydroxy column with the least hydrophobic character. From this data alone it is evident that relative to the octyl phase, the butylhydroxy phase may be suitable for hydrophobic interaction chromatography since phases for HIC are less hydrophobic than those for RPLC. The butylphenyl phase data, however, is ambiguous. The calculated hydrophobicity does not clearly indicate whether this packing shows reversed-phase or 
hydrophobic interaction character. Additional work was required to come to determine the hydrophobicity.

The polar selectivity, $q$, describes the polar character of the stationary phase. It is related to the amount of uncovered silica surface for the packing. The polar selectivity is calculated using the following equation

$$
q=m_{0}-p a_{0}
$$

where, $\quad q=$ polar selectivity

$\mathrm{m}_{\mathrm{n}}=$ hydrophobic selectivity

$a_{0}=\log$ of capacity factor for the homologous series

$\mathrm{p}=$ partition coefficient for the mobile phase components

The partition coefficient, $\mathrm{p}$, for methanol-water mixtures has a value of 0.86 . The only remaining term is $a_{0}$, which is easily calculated with the equation

$$
a_{0}=\log k
$$

The percent of organic modifier, mechanol in this case, is then plotted versus the $\log k$ values for each homologous series and regression analysis is performed. The y-intercept for the molecular residue is then calculated. This y-intercept is the $a_{0}$ value which is then substituted into Equation 8. From the paraben series data, it is clear that the butylhydroxy phase exhibits the greatest polar selectivity, followed by the octyl and butylphenyl phases, respectively.

The polar selectivity data in this work, however, do not have any real significance for two reasons. First, due to the relatively high degree of loading (surface coverage), there is very little uncovered silica surface. Second, the ligands were bonded to a silane 
intermediate rather than to silanol groups. Exposed silanols would increase the polar character of the surface and change the performance of the phase. Without the silanols, the uncovered regions are simply silica hydride $(\mathrm{Si}-\mathrm{H})$ groups which do not interact with solutes.

Since the characterization of the stationary phases specific properties vielded conclusive results for the octyl and butylhydroxy phases, but ambiguous results for the butylphenyl phase, an additional experiment was performed. Three proteins, bovine serum albumin. cytochrome $\mathrm{c}$ and ribonuclease $\mathrm{A}$, were chromatographed in order to both confirm the octyl and butylhydroxy columns' results as well as to resolve the nature of the butylphenyl phase.

By directly comparing the retention times of the proteins on each stationary phase, additional information was obtained which proved to be conclusive. As can be seen in Figures 29-37, relative to itself, each protein is retained least on the butylhydroxy phase, while the retention times are greater and almost identical on the octyl and butylphenyl phases (Table IV). This indicates that the butylhydroxy phase, having less interaction with the proteins, is less hydrophobic and therefore has more hydrophobic interaction character. This confirms the previous results determined from hydrophobicity calculations. In addition, these data support the idea that the butylphenyl phase, showing very similar retention times for each protein with those on the octyl phase, is more hydrophobic in nature. thereby being more reversed-phase. 


\section{CONCLUSION}

The two new stationary phases, as well as the reference phase, have been characterized by both chromatographic and non-chromatographic techniques. This section will summarize the findings and suggest additional work which may be considered in the future.

Estimates of the hydrophobic and polar selectivities of stationary phases can be determined by extrapolation of the natural log of the capacity factors to $100 \%$ water. The hydrophobicity of each of the stationary phases prepared in this research have been determined in this manner as well as by direct comparison of retention data. The polar selectivities have not been emphasized due to the the relatively high loading of ligands onto the solid support as well as the initial lack of significant quantities of surface silanols.

The octyl reference phase shows the greatest degree of hydrophobic character, both by hydrophobicity calculations and protein retention data, making this the most reversed-phase as expected. The butylphenyl packing is shown to possess reversed-phase character as well. The hydrophobicity calculations, however, are not definitive, but the protein retention data are. This result makes the butylphenyl phase unsuitable for hydrophobic interaction chromatography. Finally, the butylhydroxy stationary phase shows the most promising results for the original goal of preparing a hydrophobic interaction phase. This phase has the lowest relative hydrophobicity as well as the 
smallest retention times for the proteins studied. These results make the butylhydroxy packing a good candidate for use as a hydrophobic interaction stationary phase. In addition, the relatively high degree of surface coverage leads one to believe that the hydrophobicity of this phase may be decreased even more by reducing the ligand surface coverage.

Considerations for future work include modifications of both of the two new phases. By decreasing the ligand loading for the butylhydroxy phase, a packing may be developed which is even more suitable for hydrophobic interaction chromatography. Also, it should be noted that the butylphenyl column should not be immediately dismissed as a potential candidate as well. Both butyl and phenyl columns are commercially available. Each of these, when bonded to 300 angstrom silica, can be used for hydrophobic interaction chromatography. In addition, the surface coverage of the butylphenyl phase is somewhat high when compared to other commercially avilable phenyl packings. Decreasing the surface coverage of this phase may make it suitable for hydrophobic interaction chromatography as well. 


\section{REFERENCES}

Chu. C.-H.; Jonsson. E.; Auvinen, M.; Pesek, J. J.; Sandoval, J. E. Anal. Chem. 1993, 65, 808-816.

Hetem, M. J. J.; de Haan. J. W.; Classens, H. A.; van de Ven. L. J. M.; Cramers, C. A.; Kinkel, J. N. Anal. Chem. 1990, 62, 2288.

Jandera. P. J. Chromatography A, 1986, 352, 91-110.

Jandera, P. J. Chromatography .4, 1984, 314, $13-36$.

"MetaChem Technologies Liquid Chromatography Guide", 1996.

Pesek, J. J.; Matyska, M. T.; Soczewinski, E.; Christensen, P. Chromatographia, 1994, $39,520-528$.

Pesek, J. J.; Sandoval, J. E. Anal. Chem. 1991, 63, 2634-2641.

Rippel, G.; Alattyani, E.; Szepesy, L. J. Chromatography A, 1994, 668, $301-312$.

Saunders, D. L. "Chromatography", 3rd Ed., New York, 1975.

Szepesy, L.; Rippel, G. J. Chromatography A, 1994, 668, 337-344.

Yost, R. W.; Ettre. L. S.; Conlon, R. D. "Practical Liquid Chromatography-An Introduction", Perkin-Elmer, 1980. 
APPENDLX A (Tables) 
Table I

COMLPARISON OF RPLCALD HIC

Parameter

Interaction

Stationary Phase

Ligand Type

Ligand Density

Hydrophobicity

Mobile PhaseType

Proteins
HIC
Dispersion
RPLC
Dispersion

Long alkyl chains

Shor alkyl chains, Phenyls

Low

High

Strong

Moderate

Aqueous-organic

Aqueous (buffers)

Structure on Stationary Unfolded $\quad$ Folded
Phase

Dominant Retention Feature Overall hydrophobicity Surface hydrophobicity 
Table II

\section{SURFACE COVERAGE}

\begin{tabular}{|c|c|c|c|}
\hline & $\% C(E A)$ & Corrected $^{\text {l }}$ & $\mathrm{umol} / \mathrm{m}^{2}$ \\
\hline Burylhydroxy & 2.87 & 2.17 & 4.41 \\
\hline Butylphenyl & 4.25 & 3.55 & 2.90 \\
\hline Octyl & 3.18 & 2.48 & 2.51 \\
\hline
\end{tabular}

${ }^{\mathrm{I}}$ After subtracting $\% \mathrm{C}$ present before bonding (0.7\%) 
Table III

\section{HYDROPHOBICITY AND POLAR SELECTIVTY DATA}

Column

Burylhydroxy

Homologous Series

parabens

dialkyl phthalates

benzenes
Butylphenyl

$m_{2} \quad q$

$0.67-0.27$

$0.77-0.55$
$-0.76 \quad-1.77$

Octyl

$\begin{array}{cc}\mathrm{m}_{2} & \mathrm{q} \\ 0.77 & 0.79 \\ 2.60 & 2.70 \\ & \\ -1.01 & -1.06\end{array}$

$\underline{m}_{2} \quad q$

$0.61 \quad 0.12$

$2.76 \quad 2.37$

$-0.55 \quad-1.27$ 
Table IV

PROTEIN RETENTION DATA

Butylhydroxy Butylphemyl Octyl

Protein

$\mathrm{R}_{\mathrm{r}}(\mathrm{min})$

$\underline{R_{1}(\min )}$

$\underline{R}_{r}(\min )$

RNase

2.0

14.7

14.5

cyto C

14.1

17.4

17.2

BSA

18.2

19.7

19.6 
APPENDLX B (Figures) 


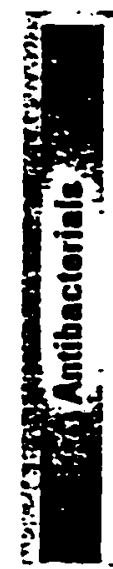

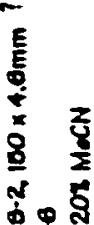

의

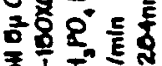

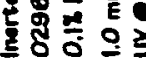

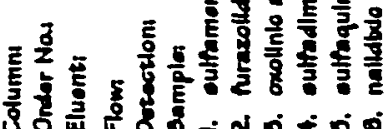

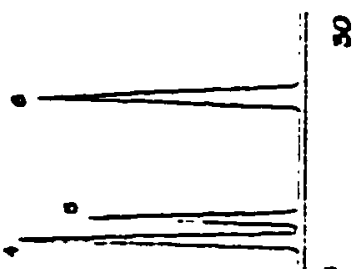



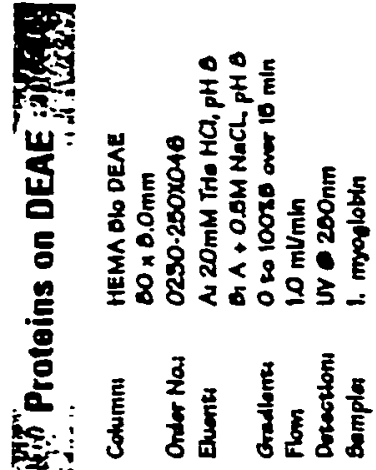
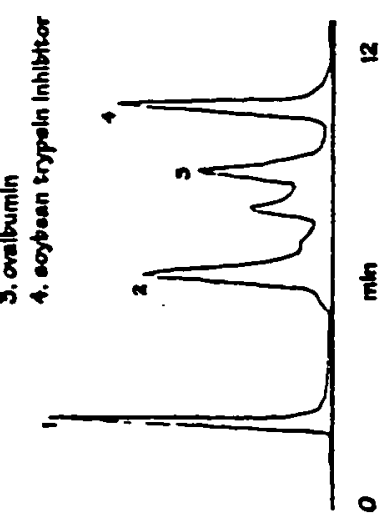

늘

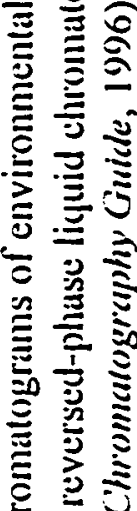

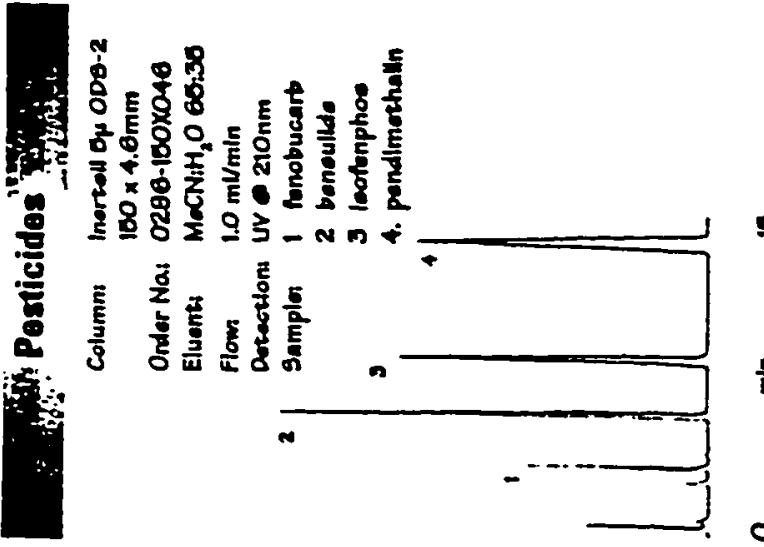

총

要 范

e

资

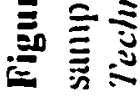




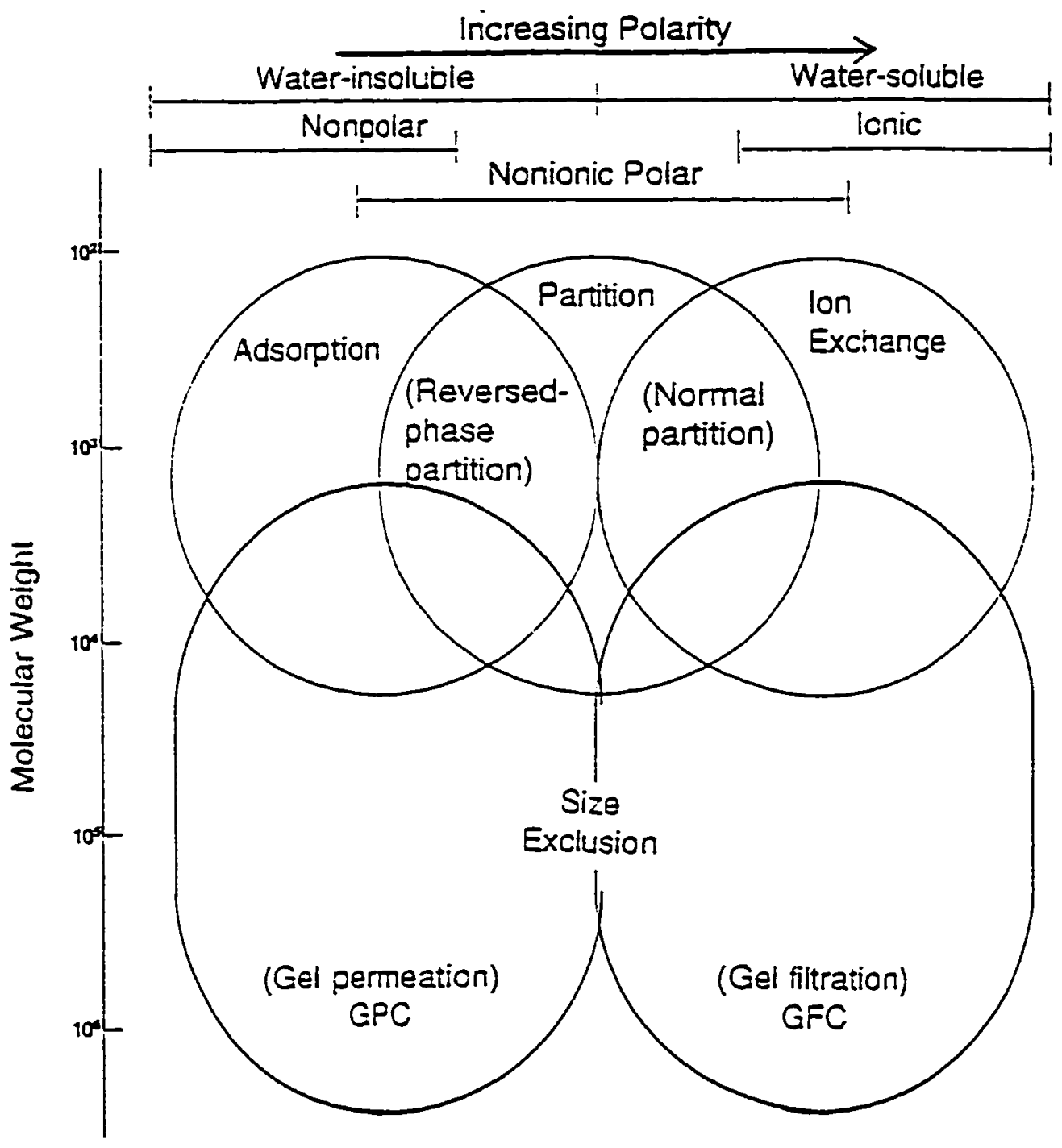

Figure 2. Chromatography modes and their applications (reprinted from D. L. Saunders, Chromatography, 3rd Ed., p.81, New York, 1975). 


\section{Methyl, 6}

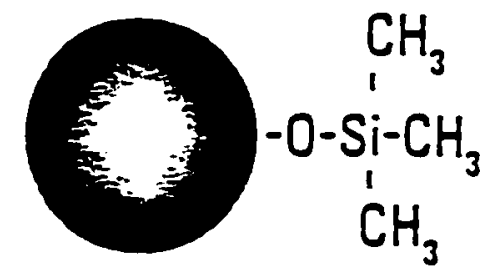

\section{Octyl. B}

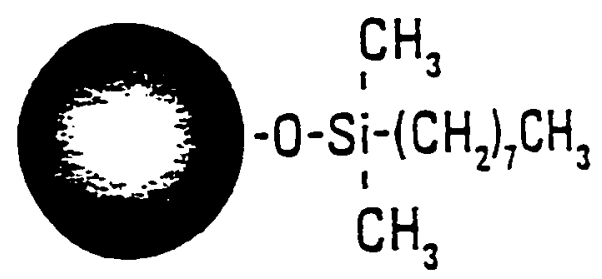

\section{ODS, 618}

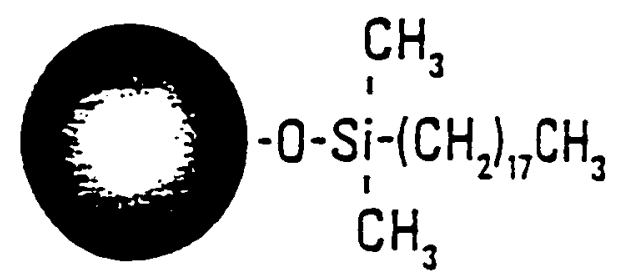

Figure 3. HPLC silica bonded reversed-phases chromatography (reprinted from MetaChem Technologies Liquid Chromatography Guide, 1996). 


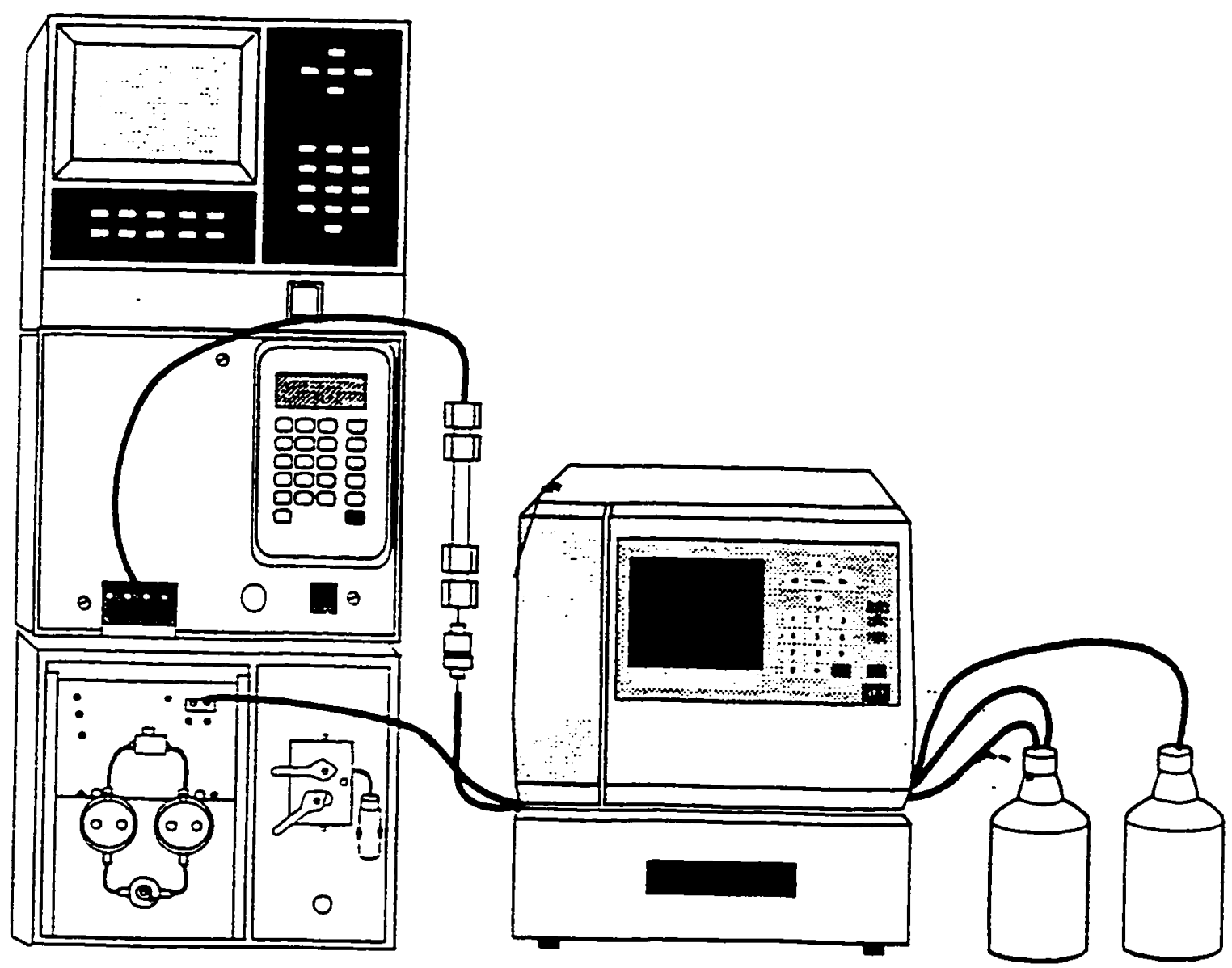

Figure 4. Chromatographic system. 
(1) $n$-alkyl-p-hydroxybenzoates (parabens)<smiles>CC(=O)c1ccc(O)cc1</smiles><smiles>O=C([O-])c1ccc(O)cc1</smiles><smiles>CCCCCCC(=O)c1ccc(O)cc1</smiles><smiles>CCCCCCC(=O)c1ccc(O)cc1</smiles>

mechyl parsbes

propvl paraien

buryl parabes

(2) dialkyl phthalates<smiles>COC(=O)c1ccccc1C(C)=O</smiles>

dimethyl phthalate

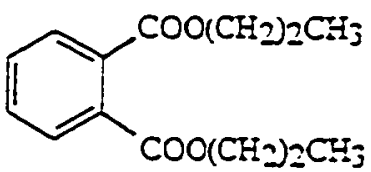

dipropyl phthalare<smiles>CCOC(=O)c1ccccc1C(=O)OCC</smiles>

diethyl pathalate<smiles>CCCCCCC(=O)c1ccccc1C(=O)OCC</smiles>

diburyl pintbalare

(3) benzene homologues<smiles>c1ccccc1</smiles>

beazene<smiles>Cc1ccccc1</smiles>

soluene<smiles>Cc1cccc(C)c1</smiles>

m-xyiene

Figure 5. Series of homologues used to characterize stationary phases. 


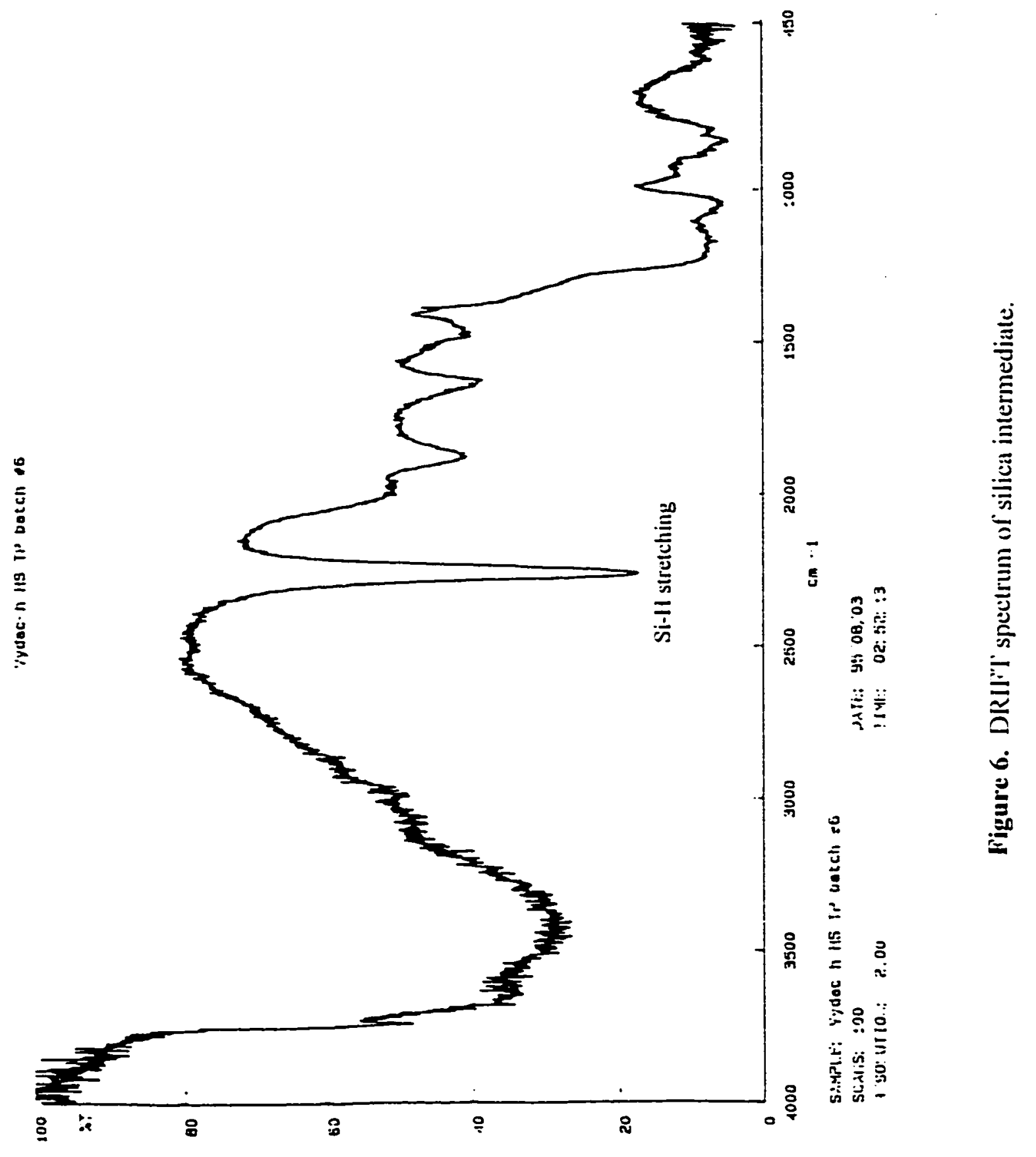




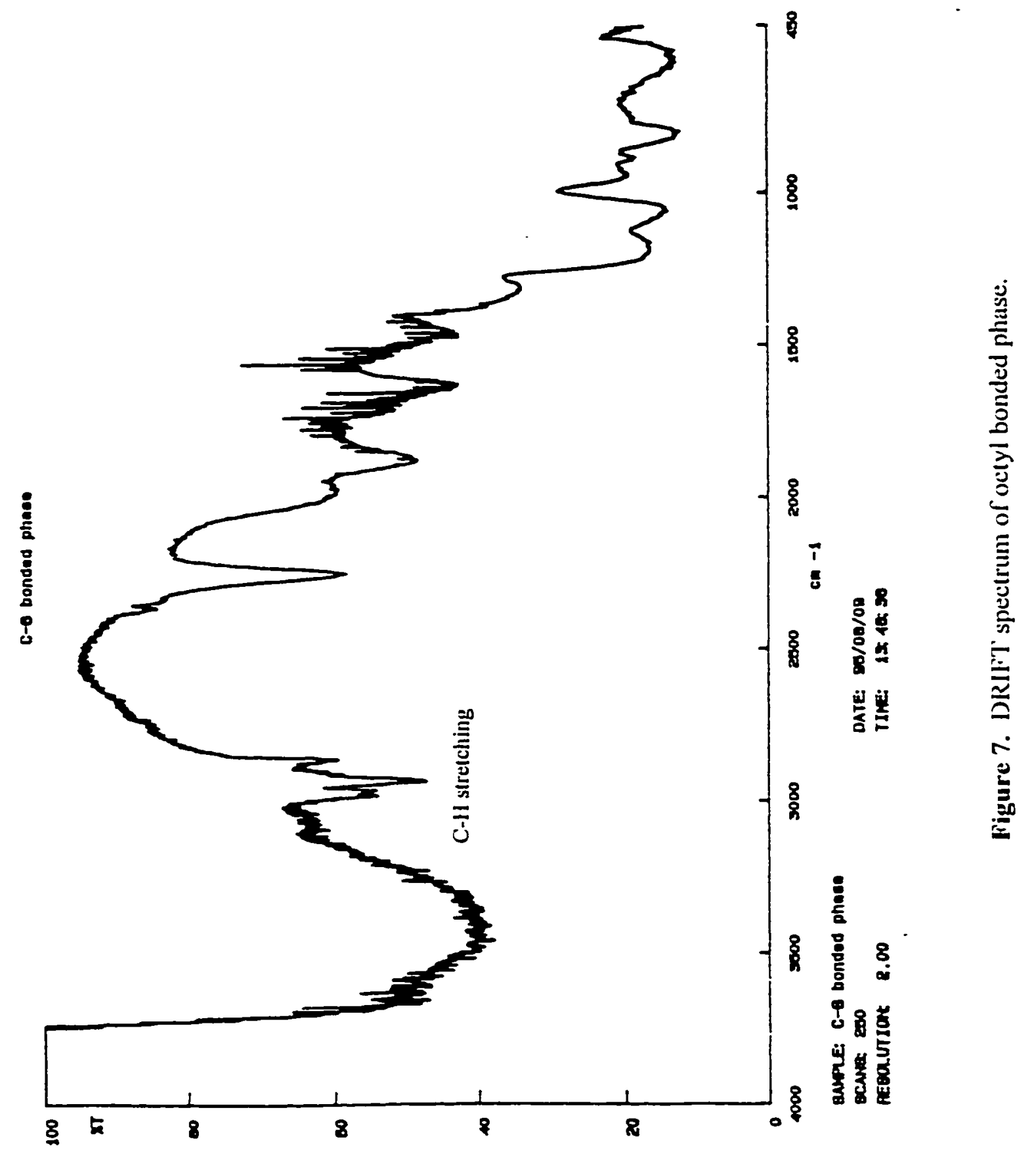




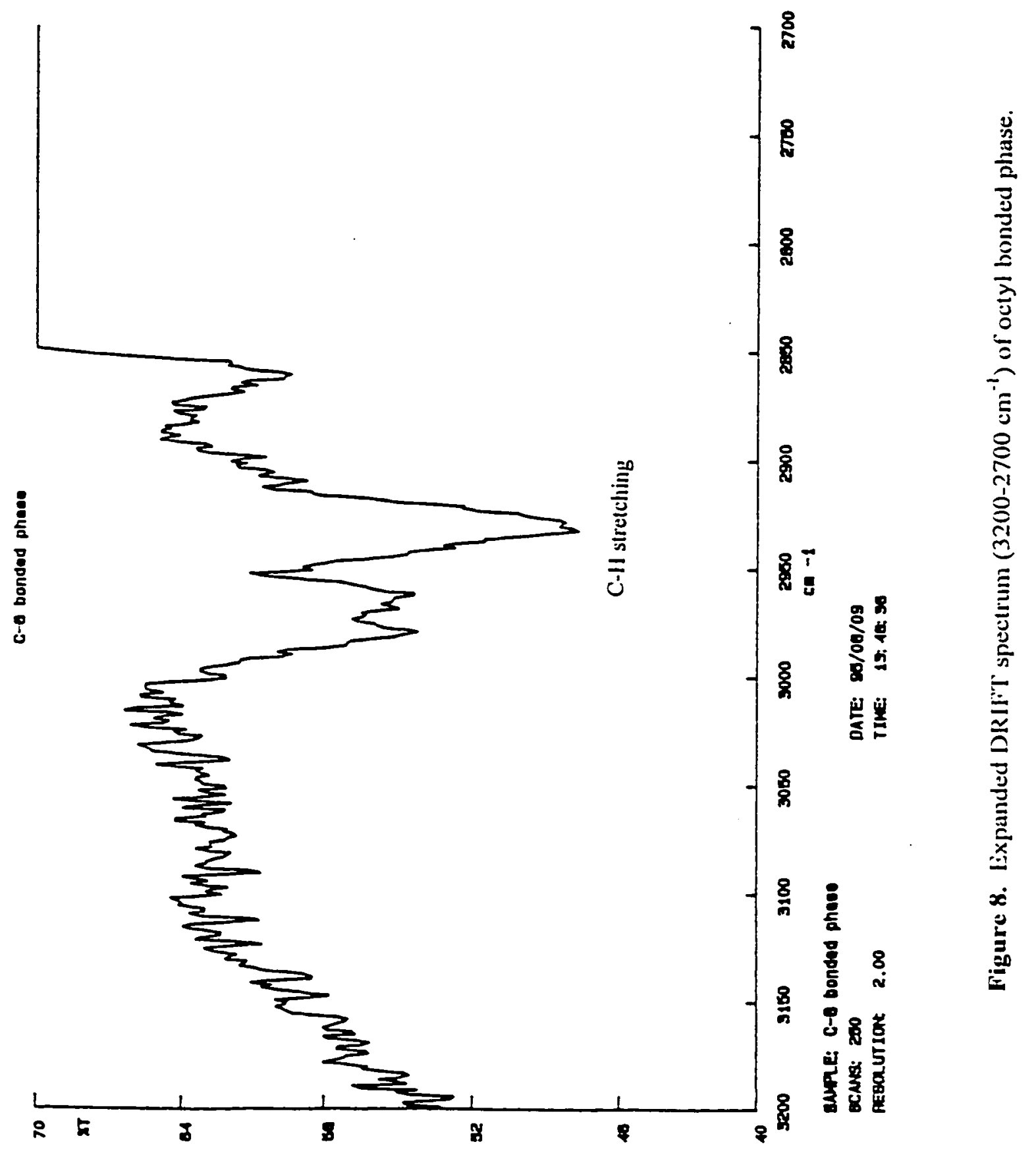




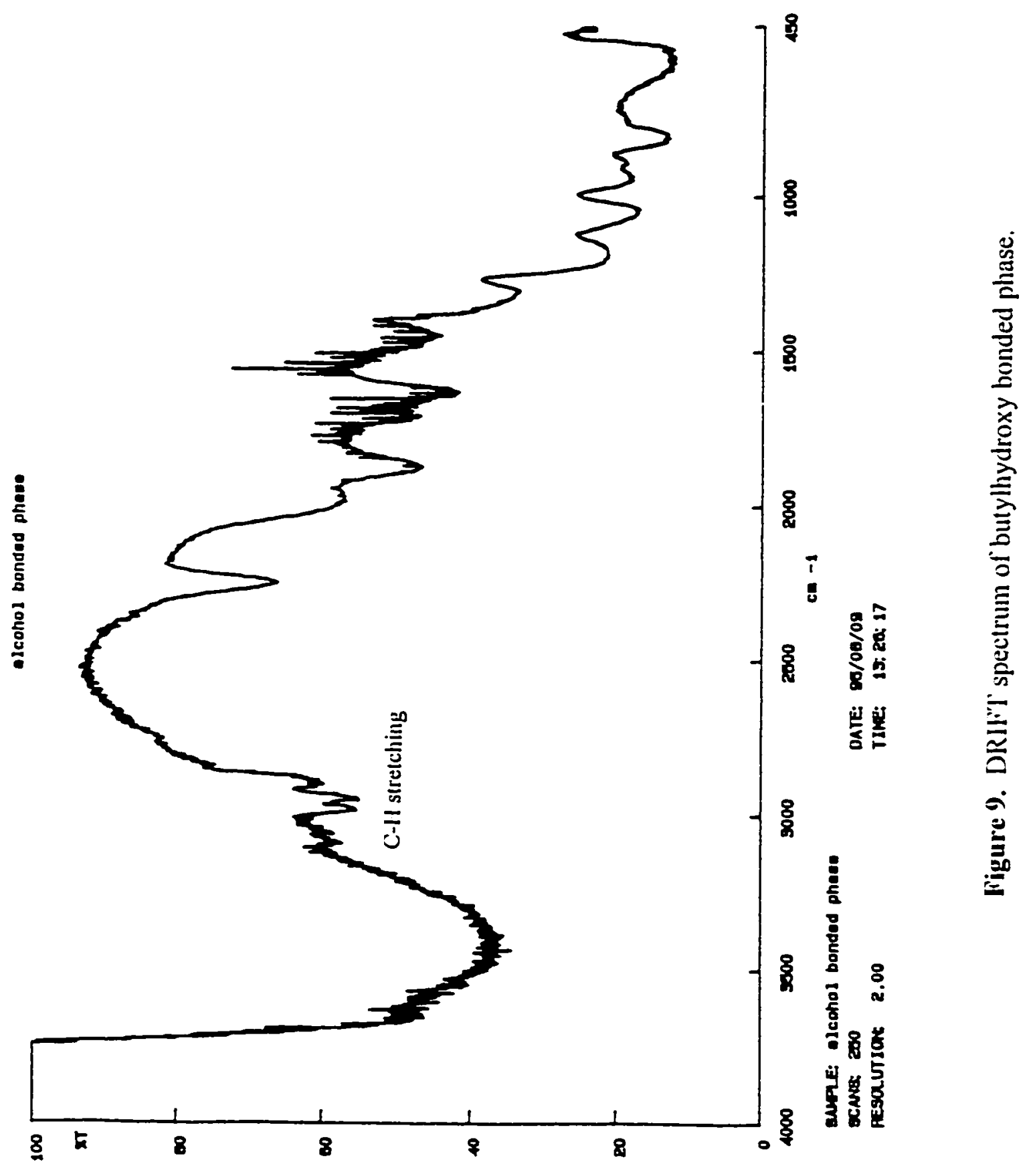




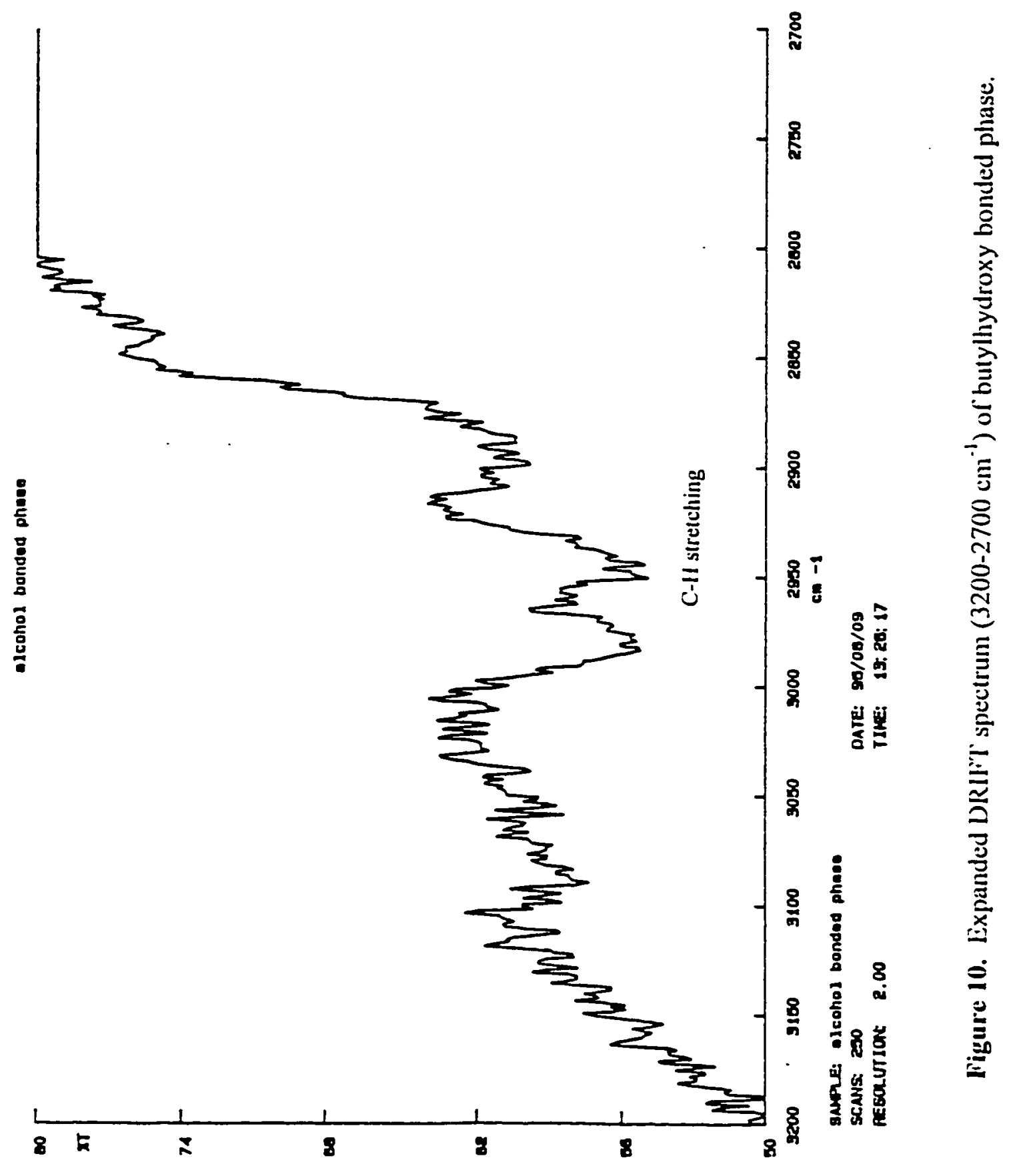




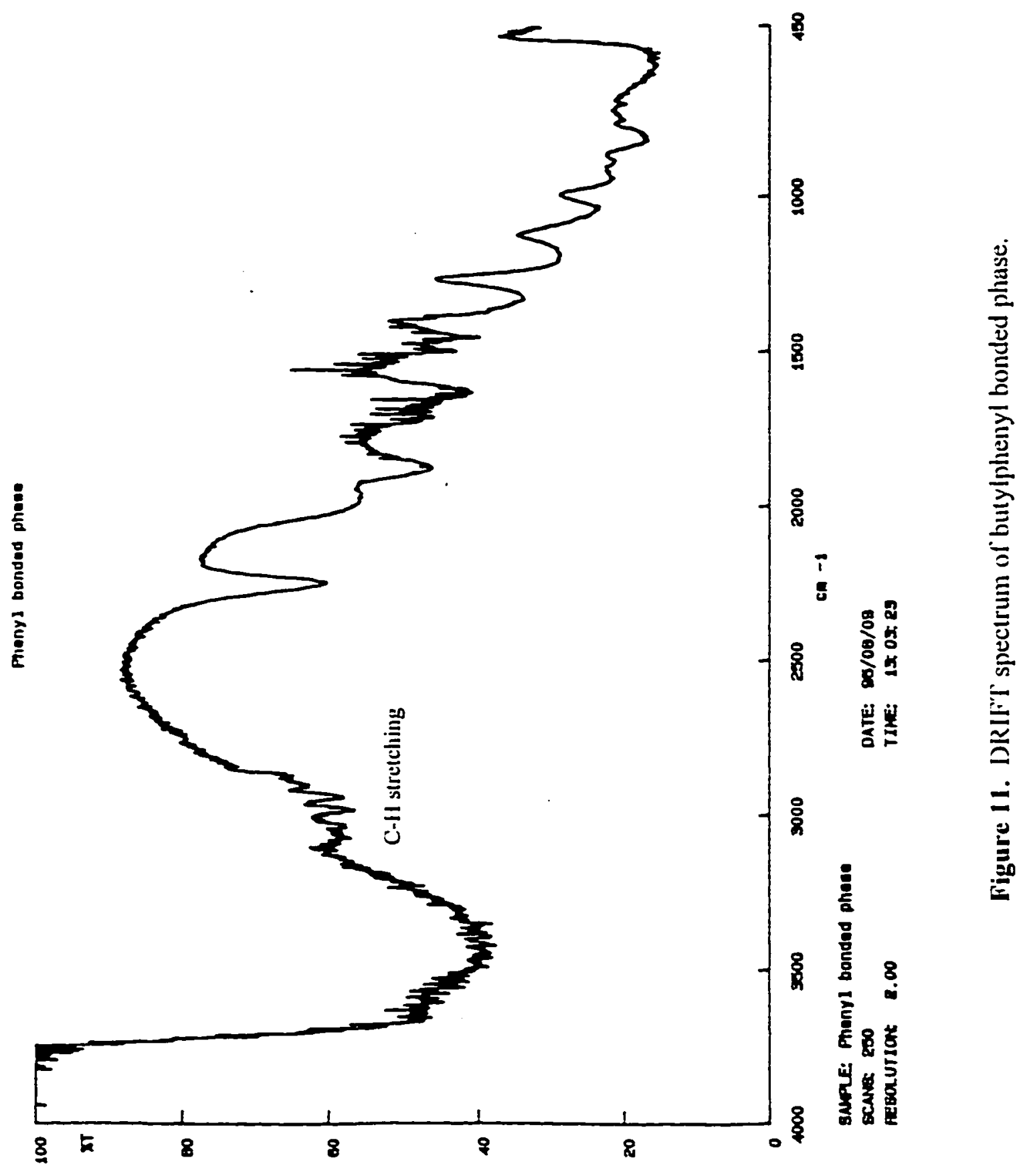




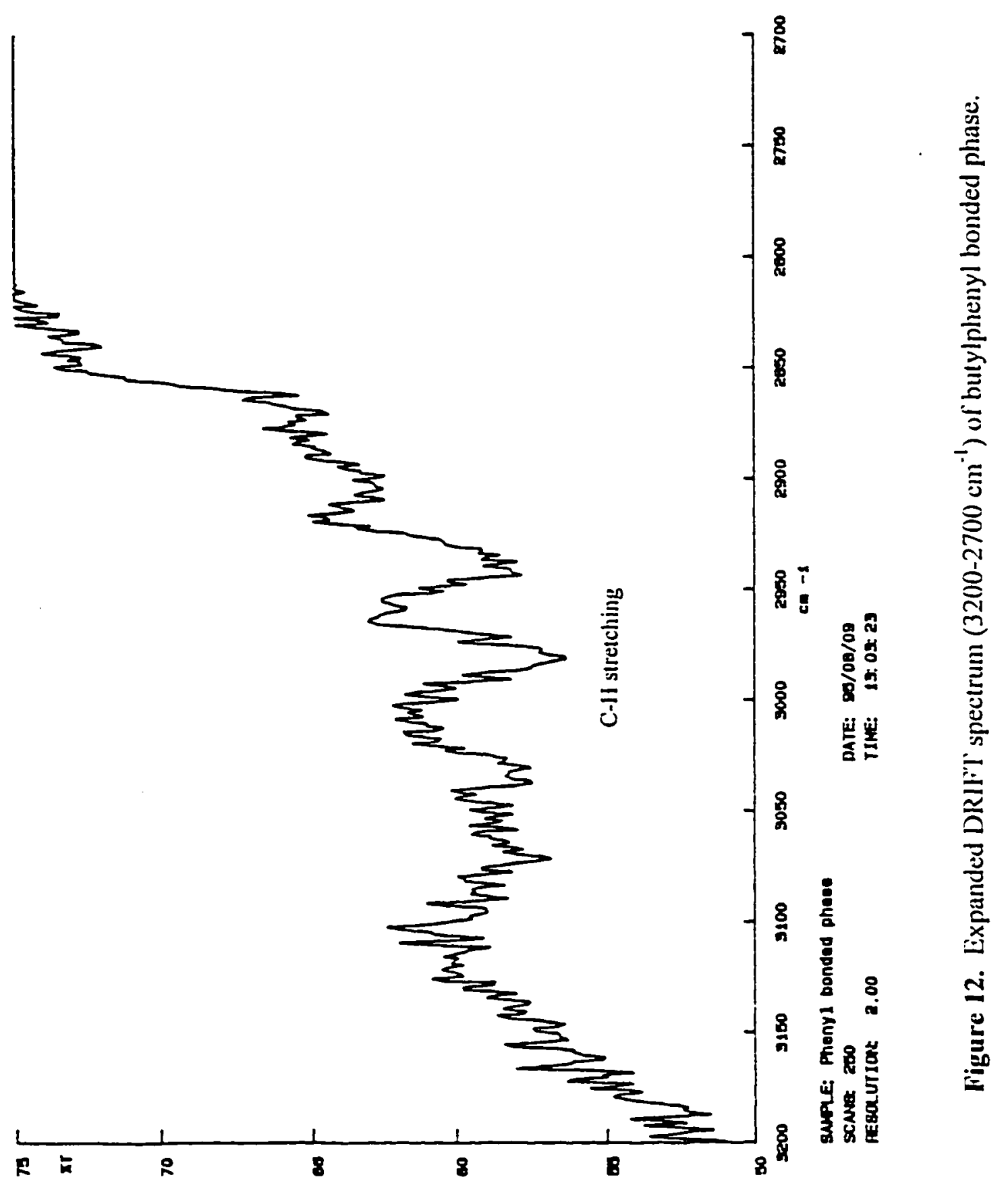




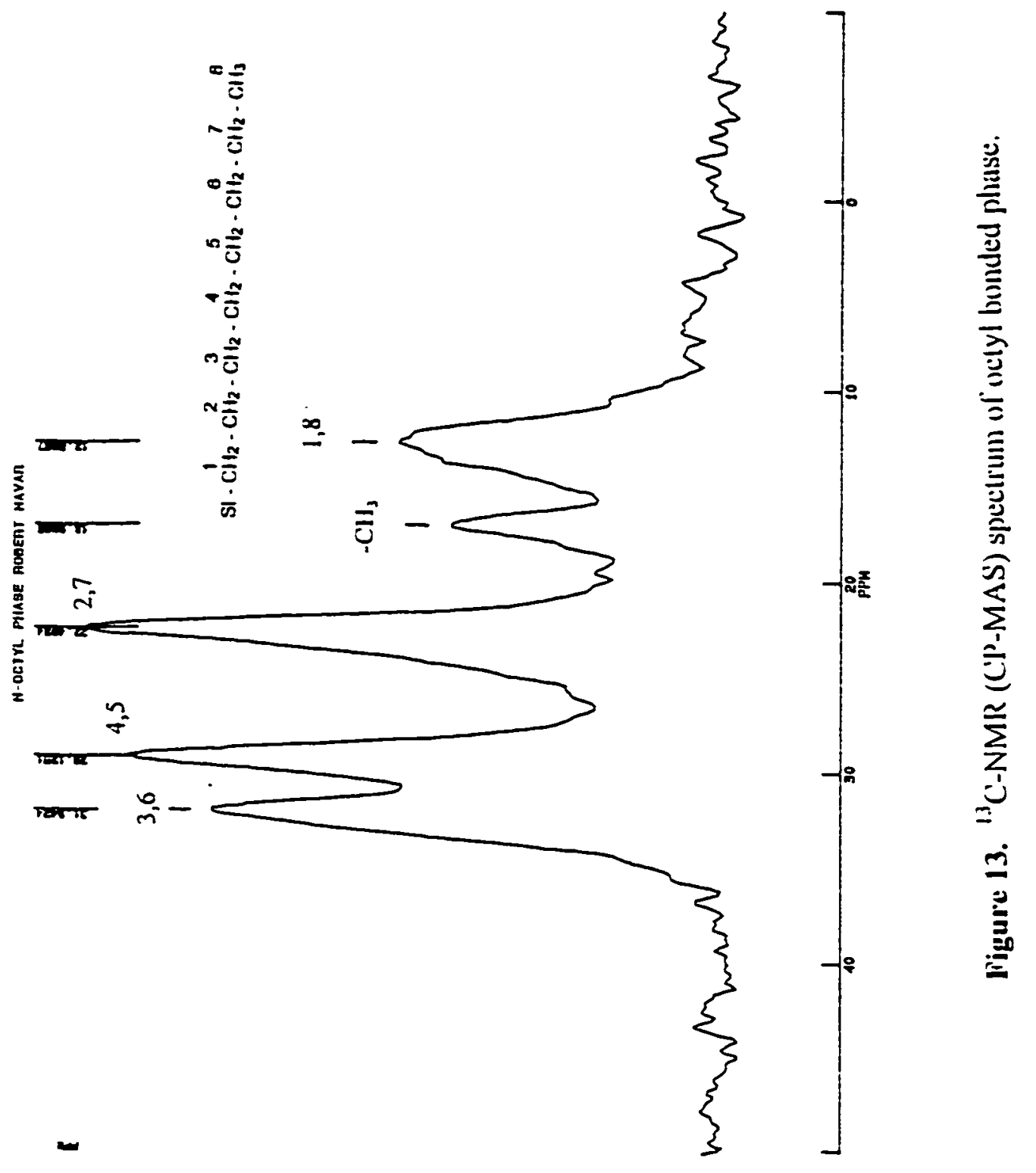



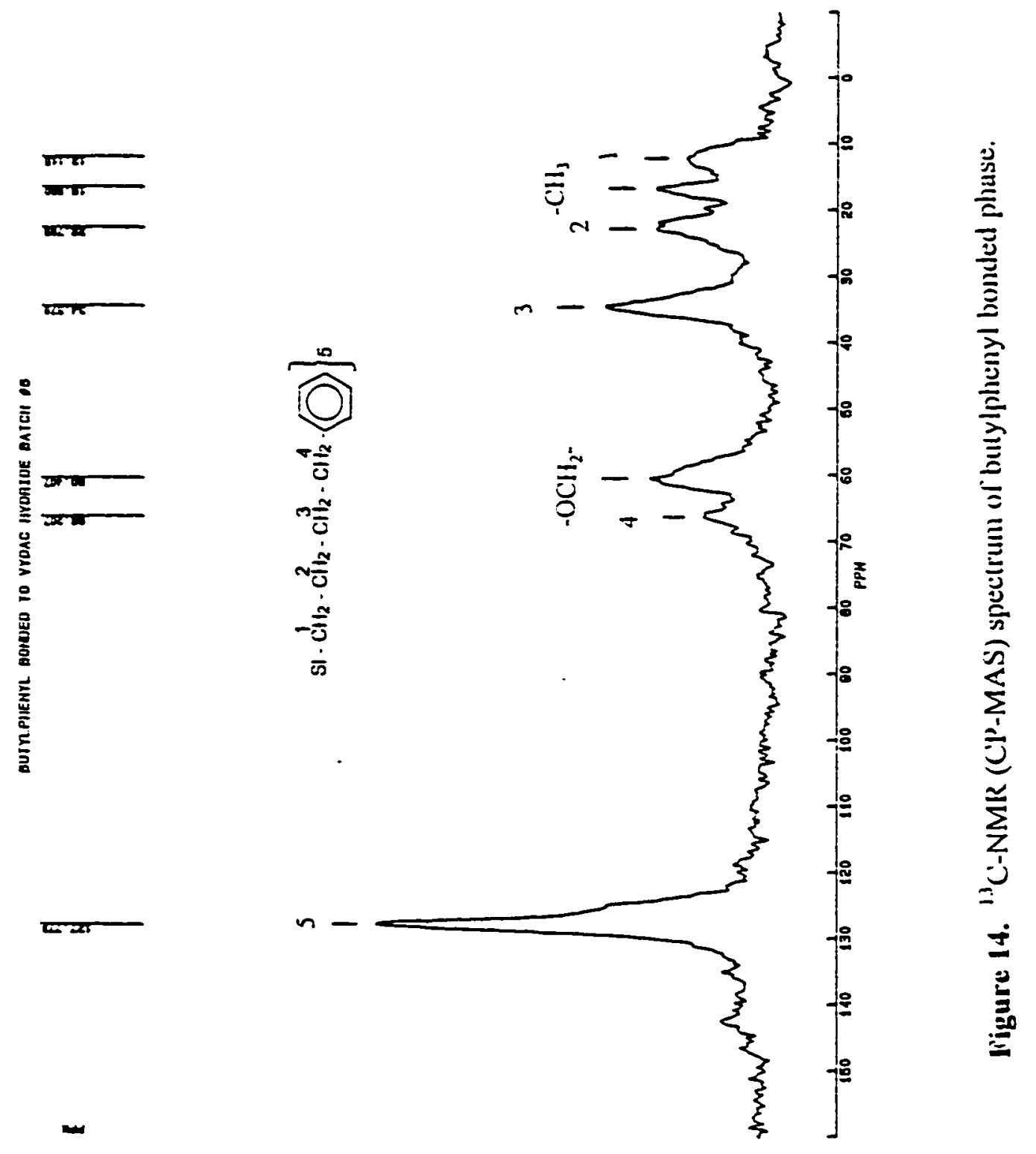


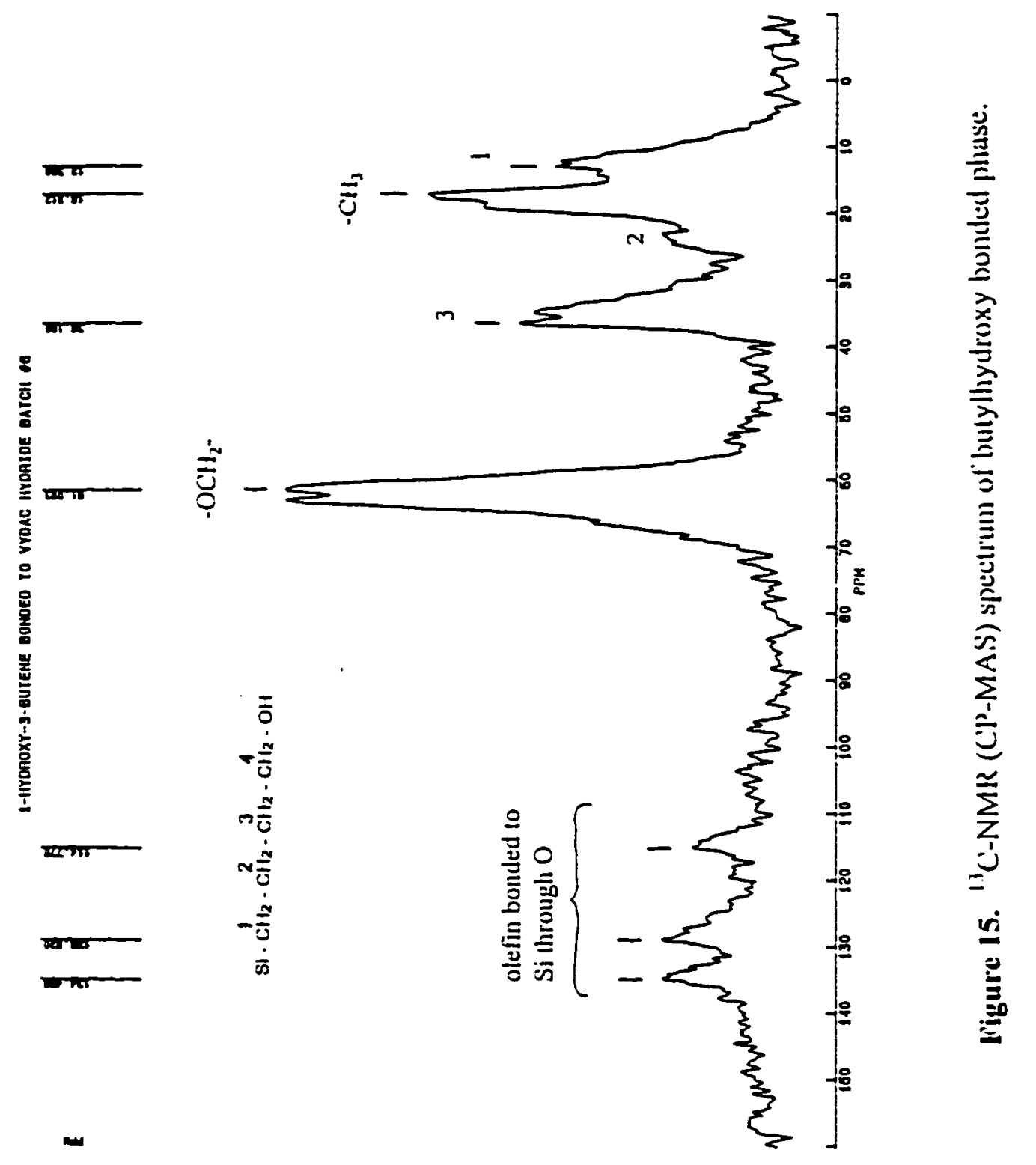



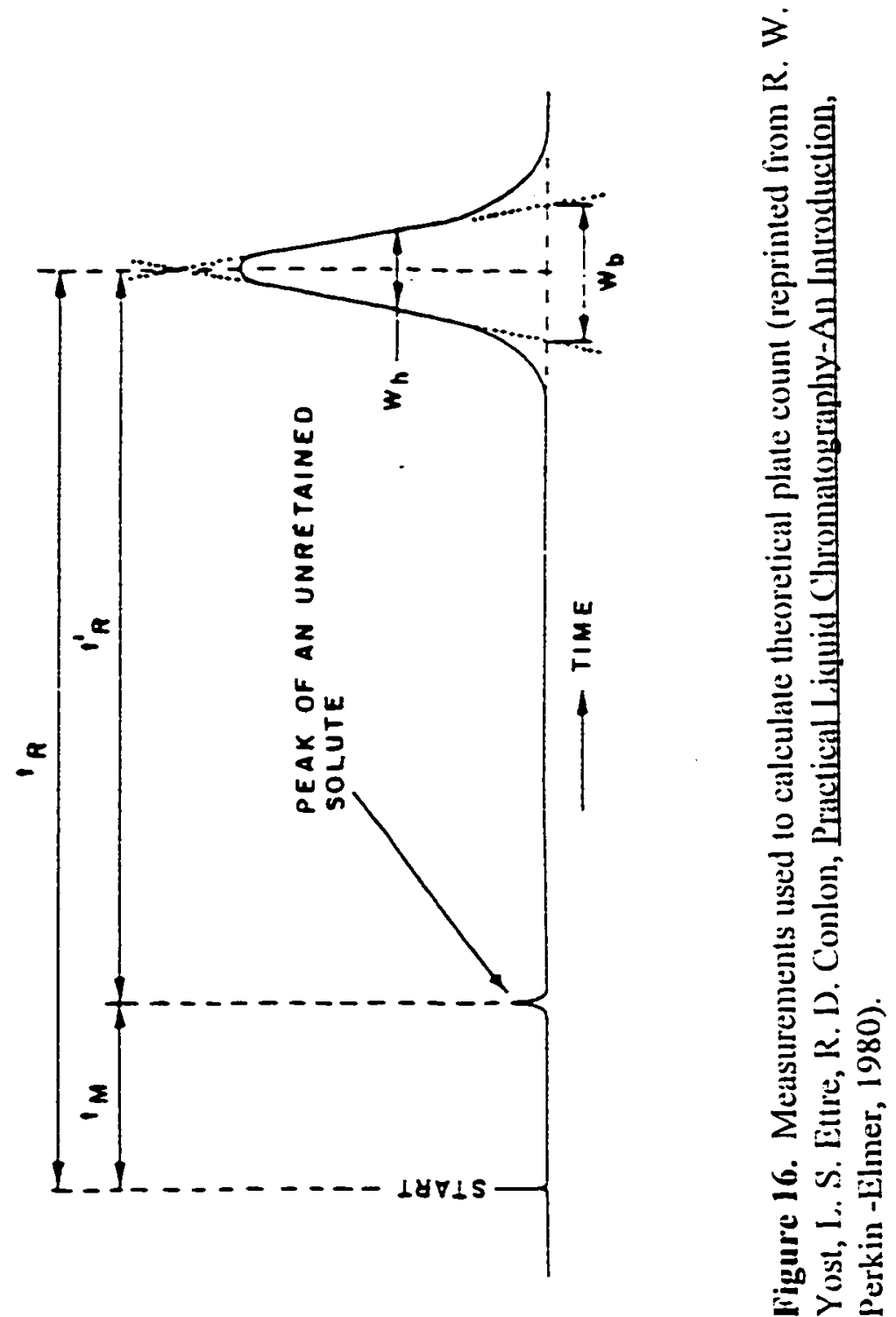


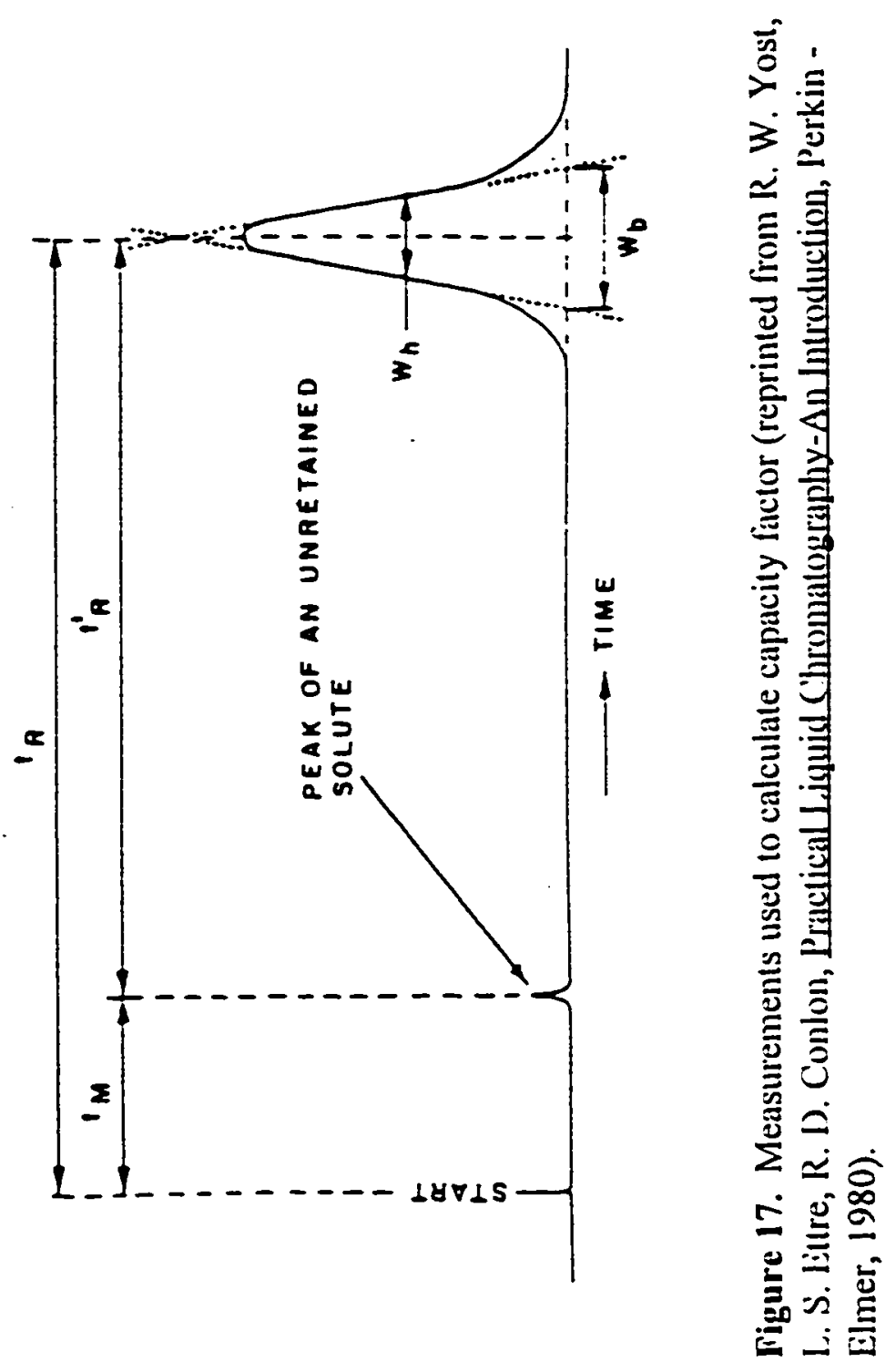



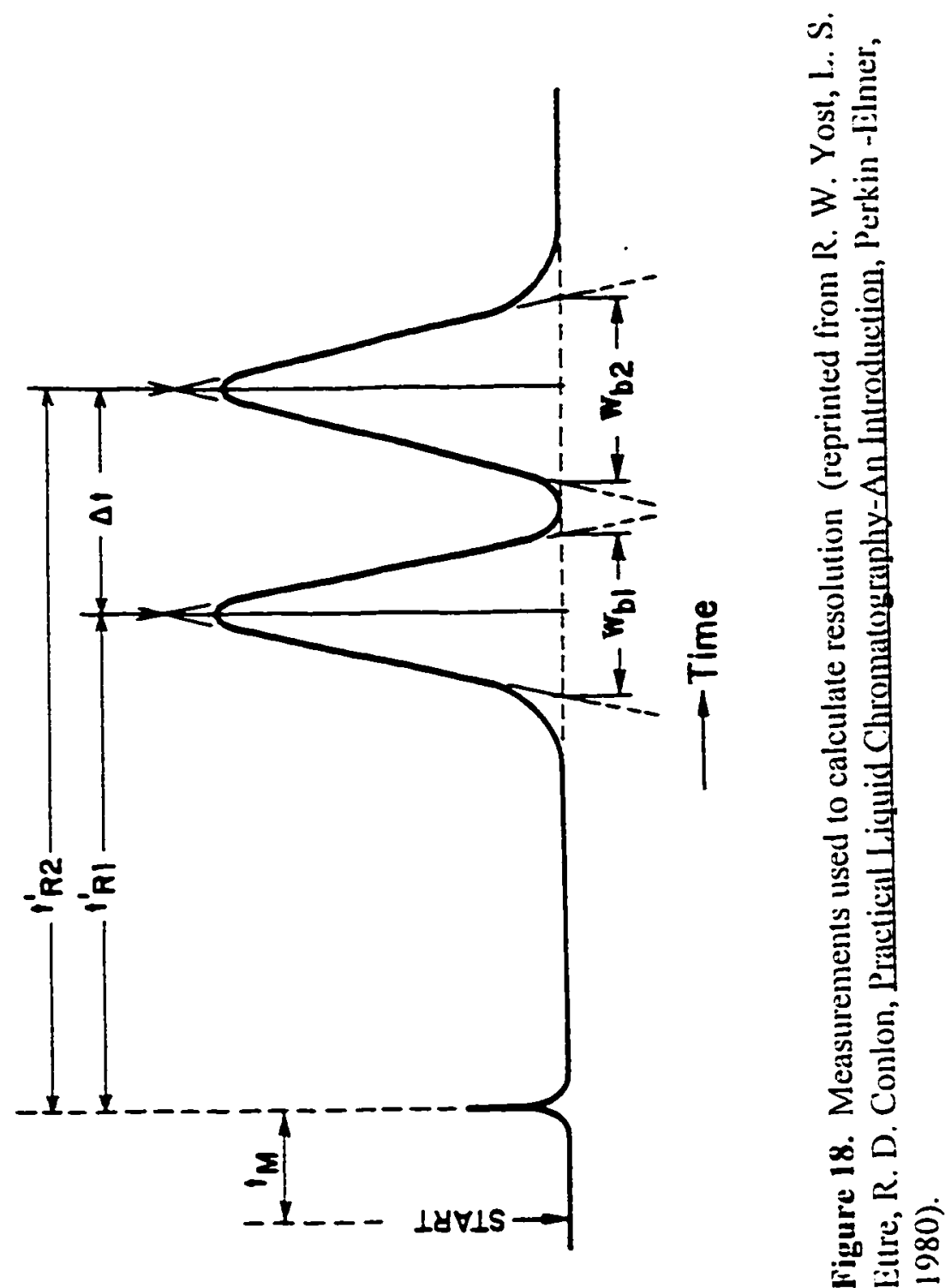


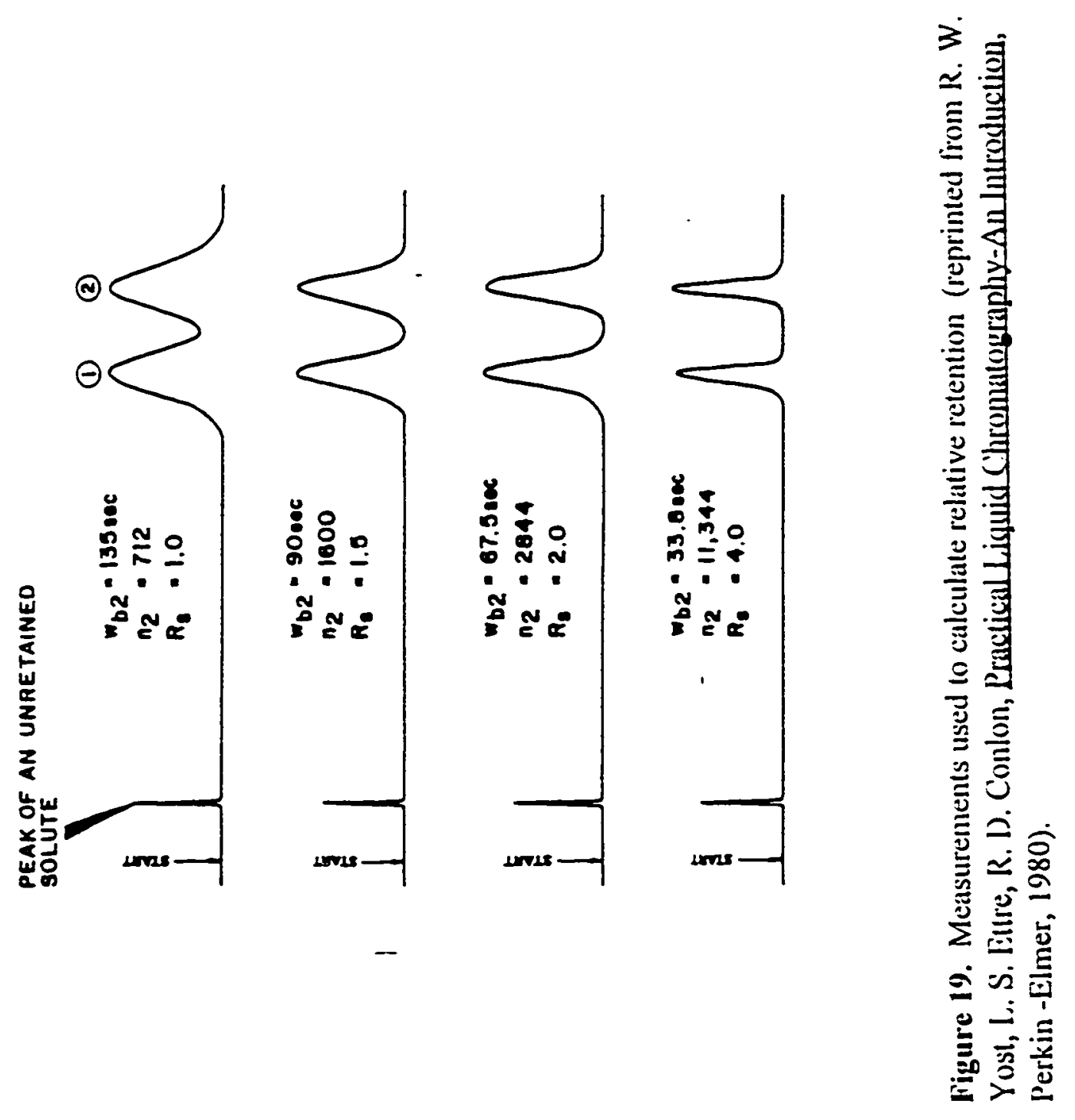




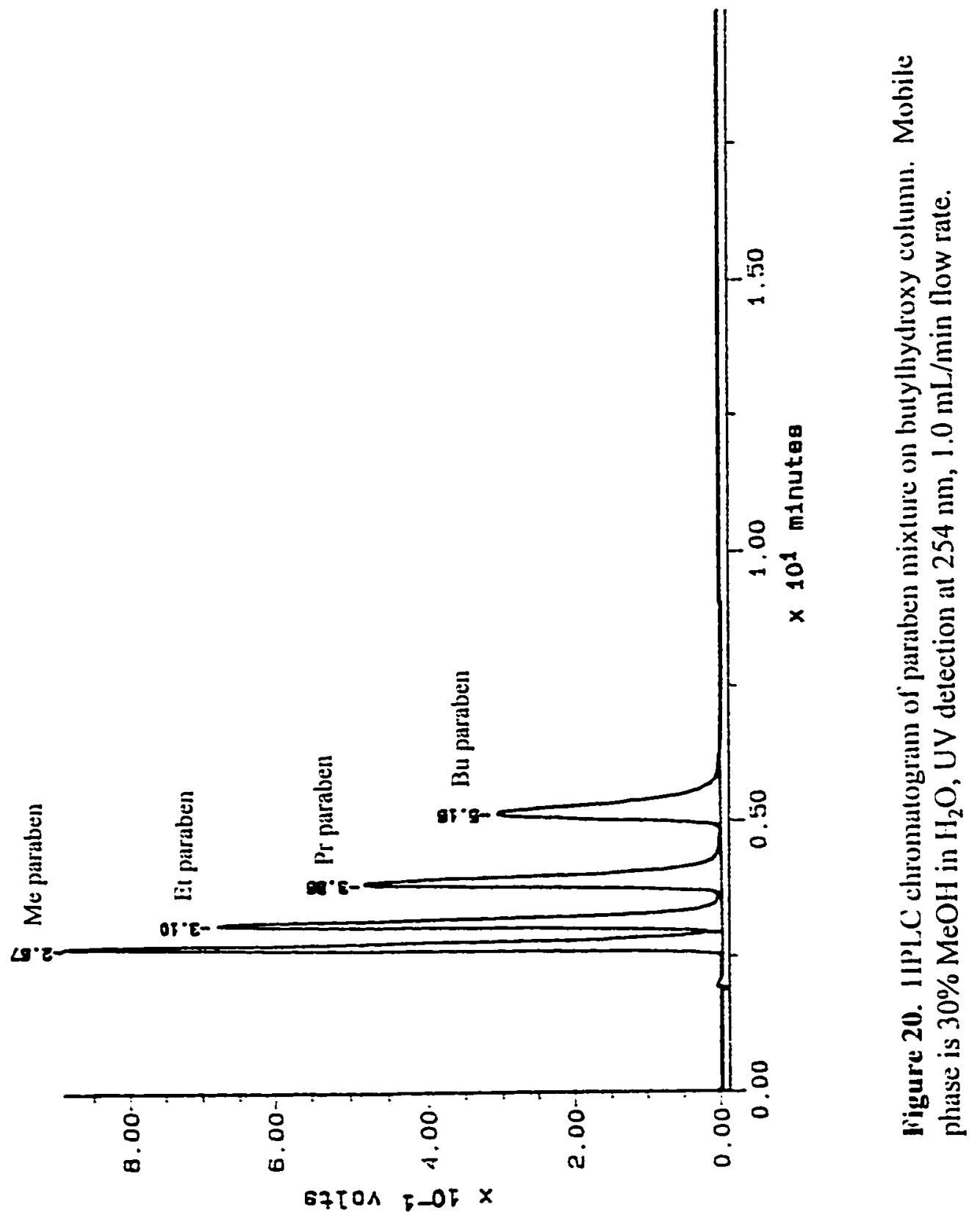




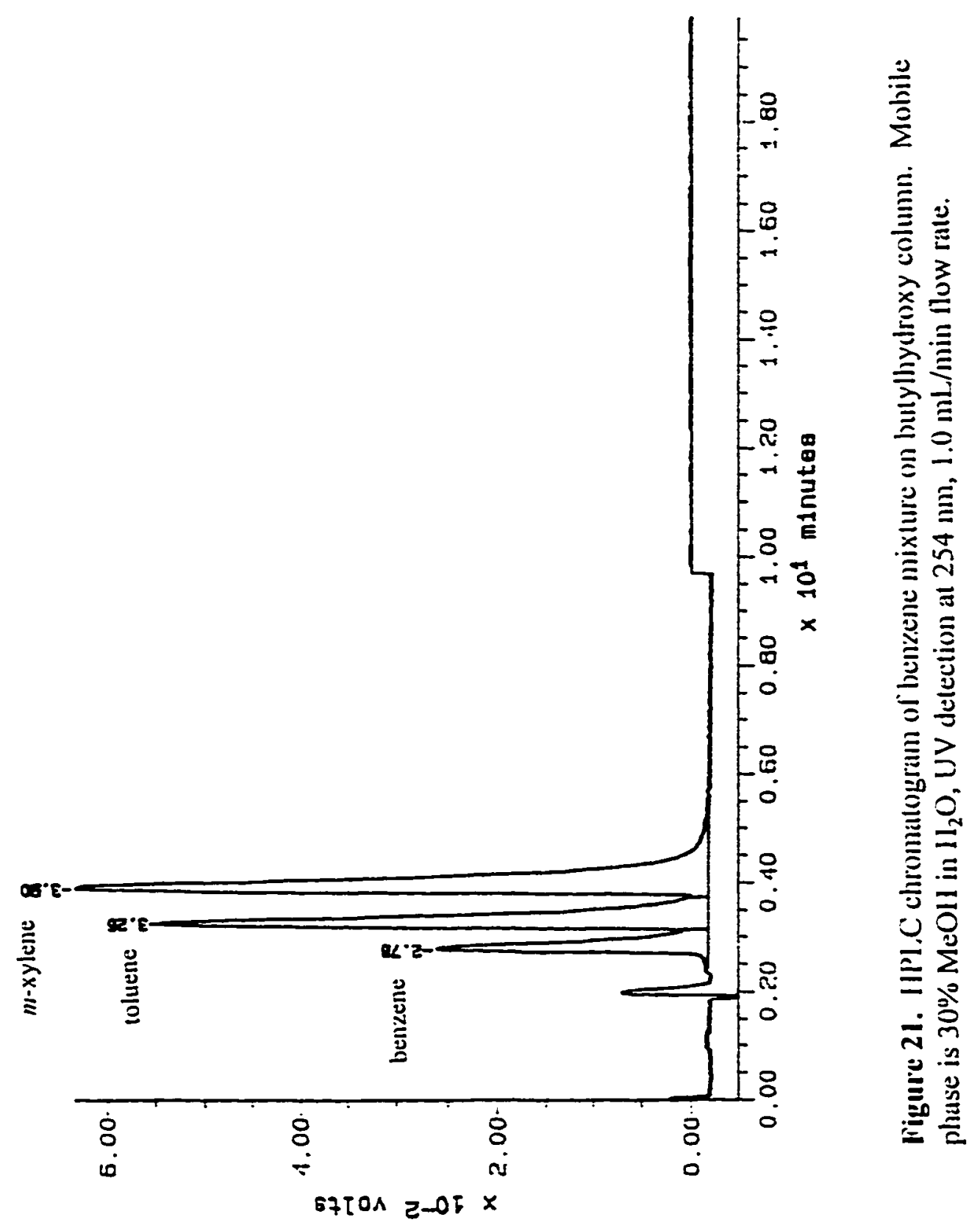




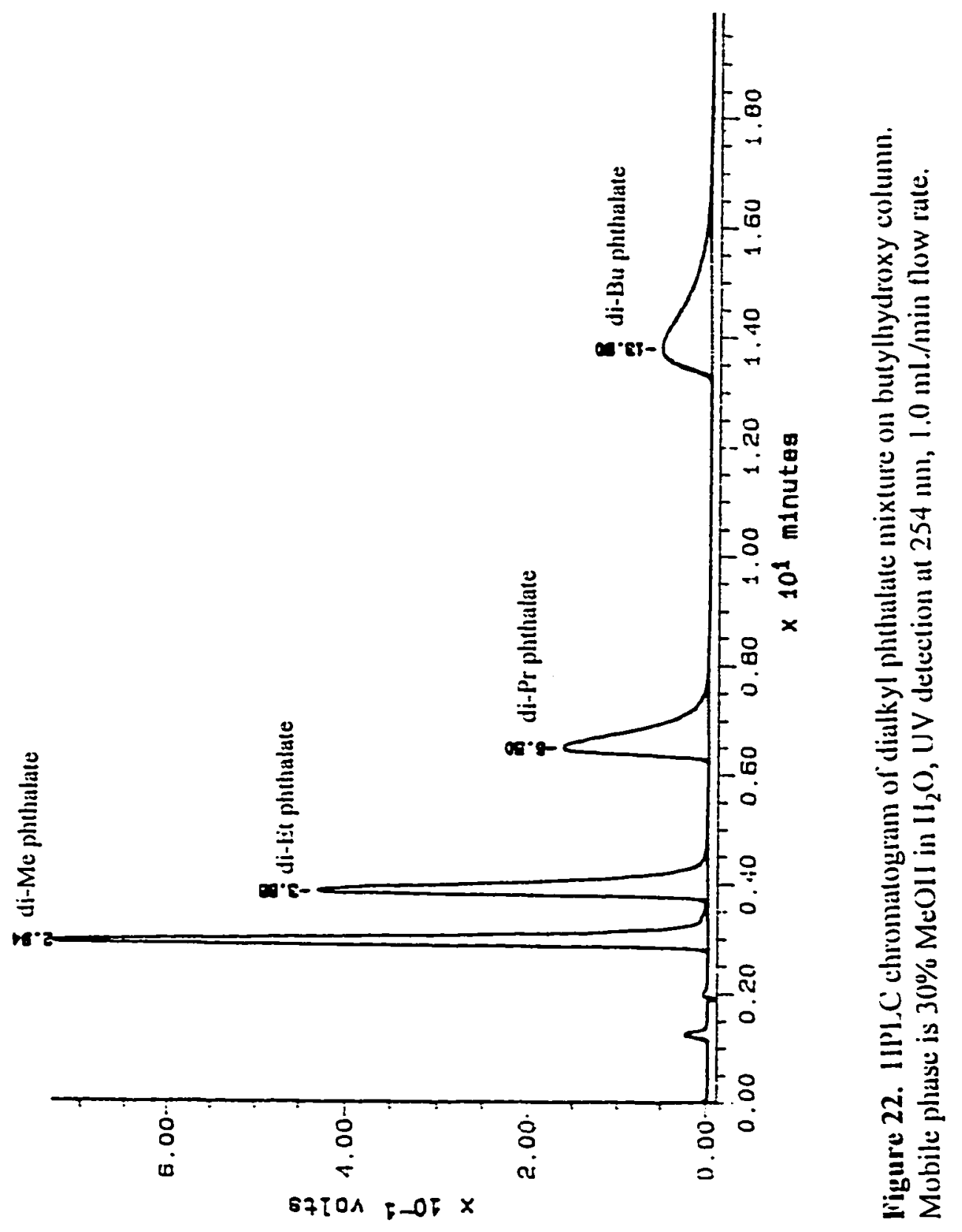




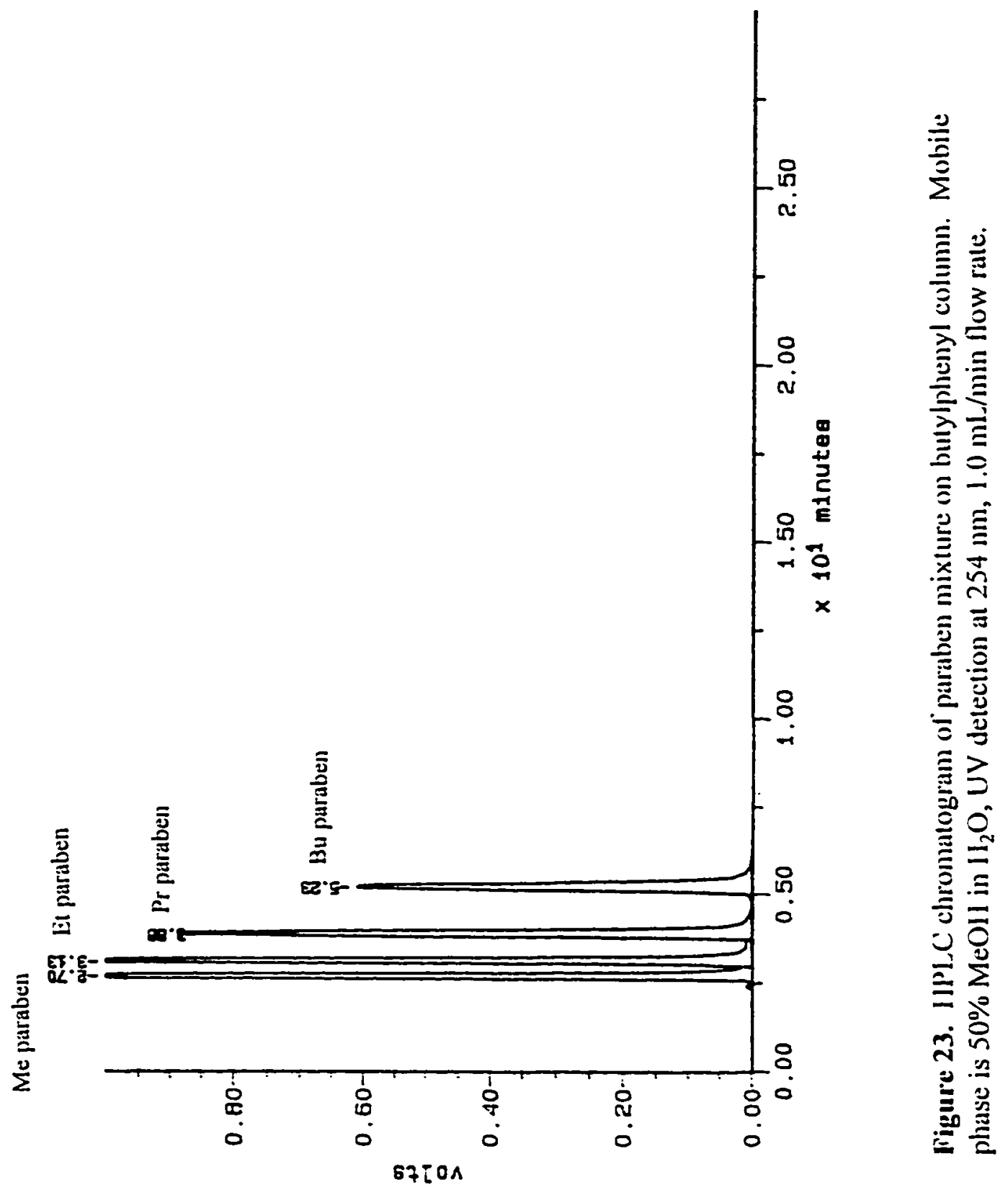




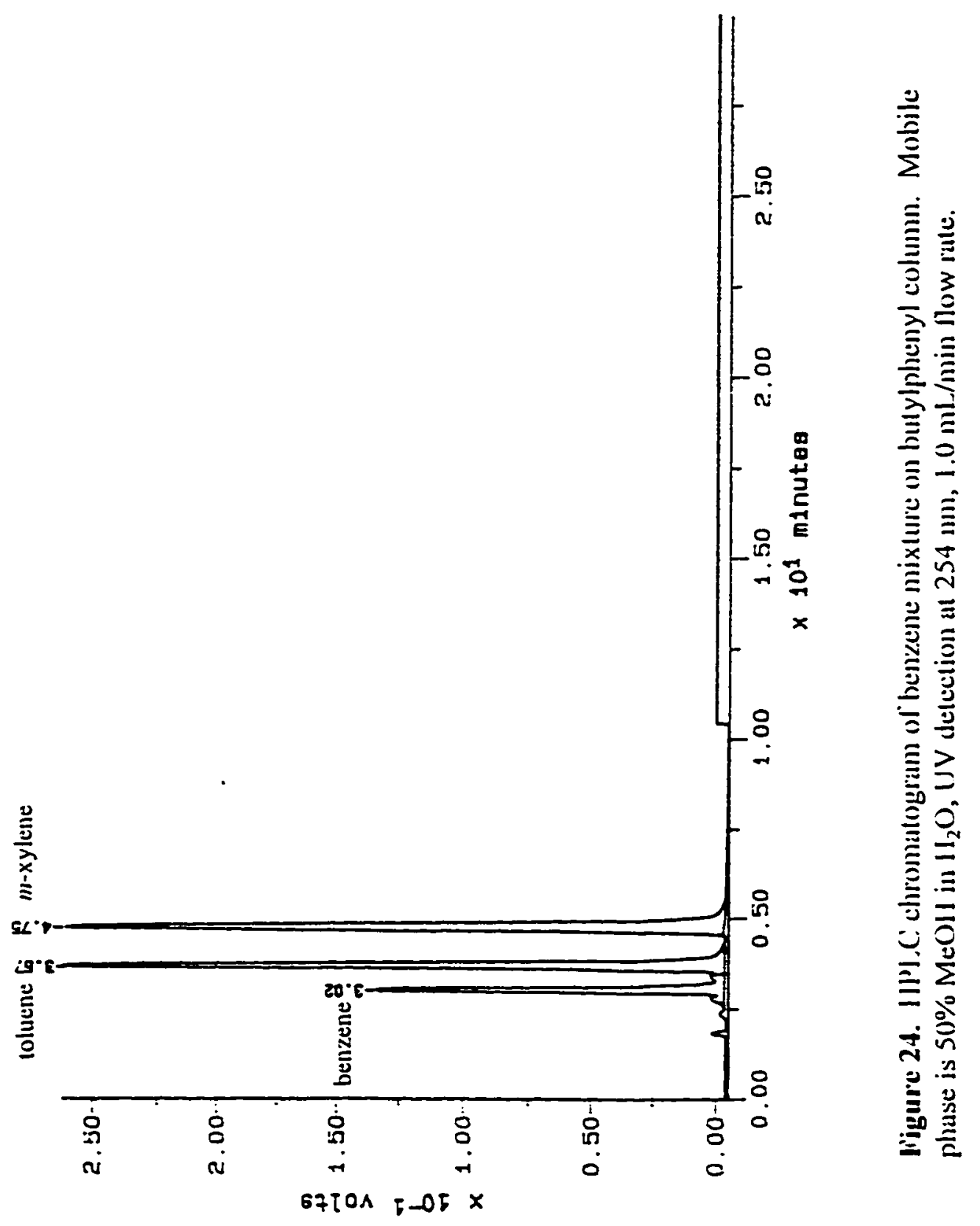




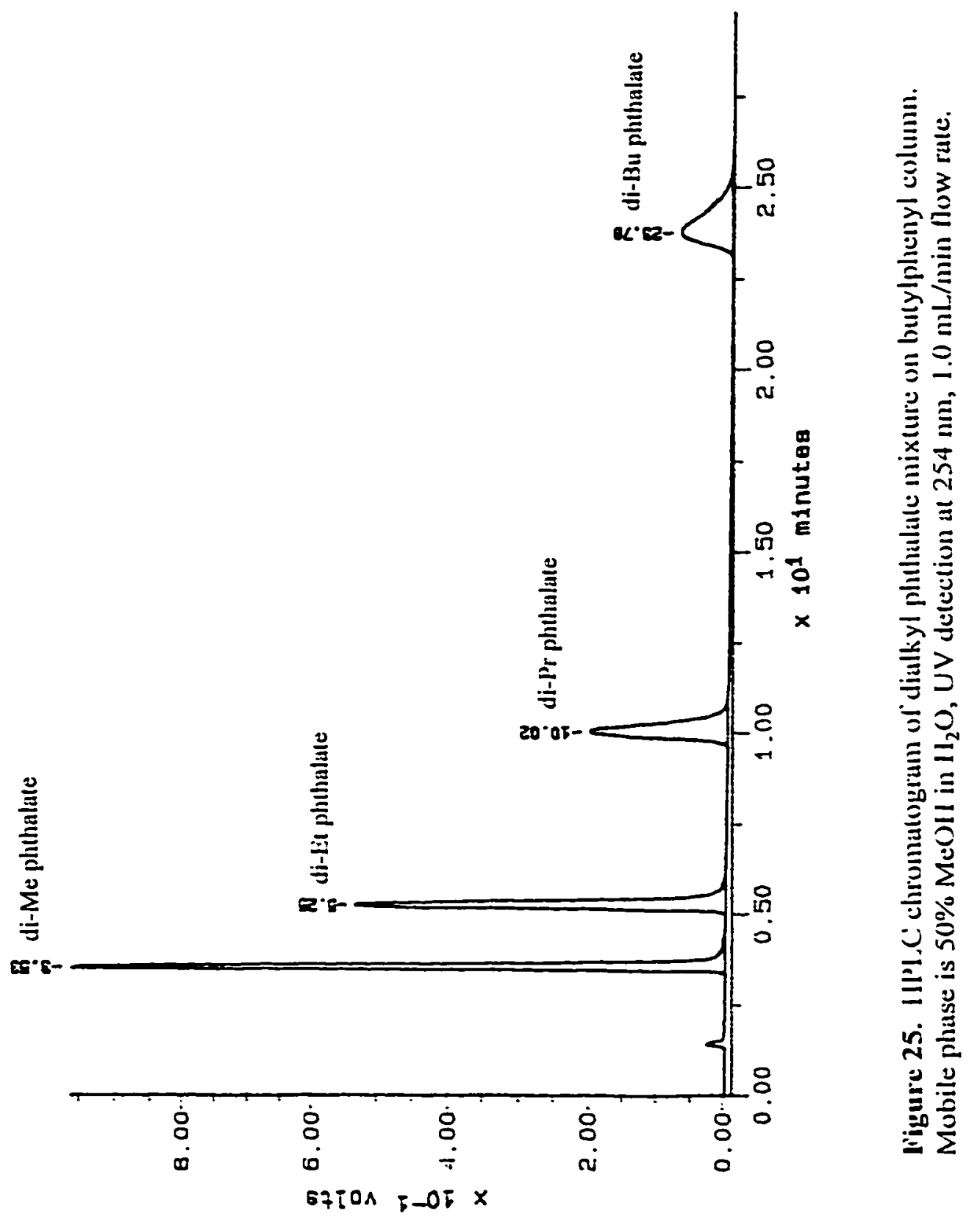




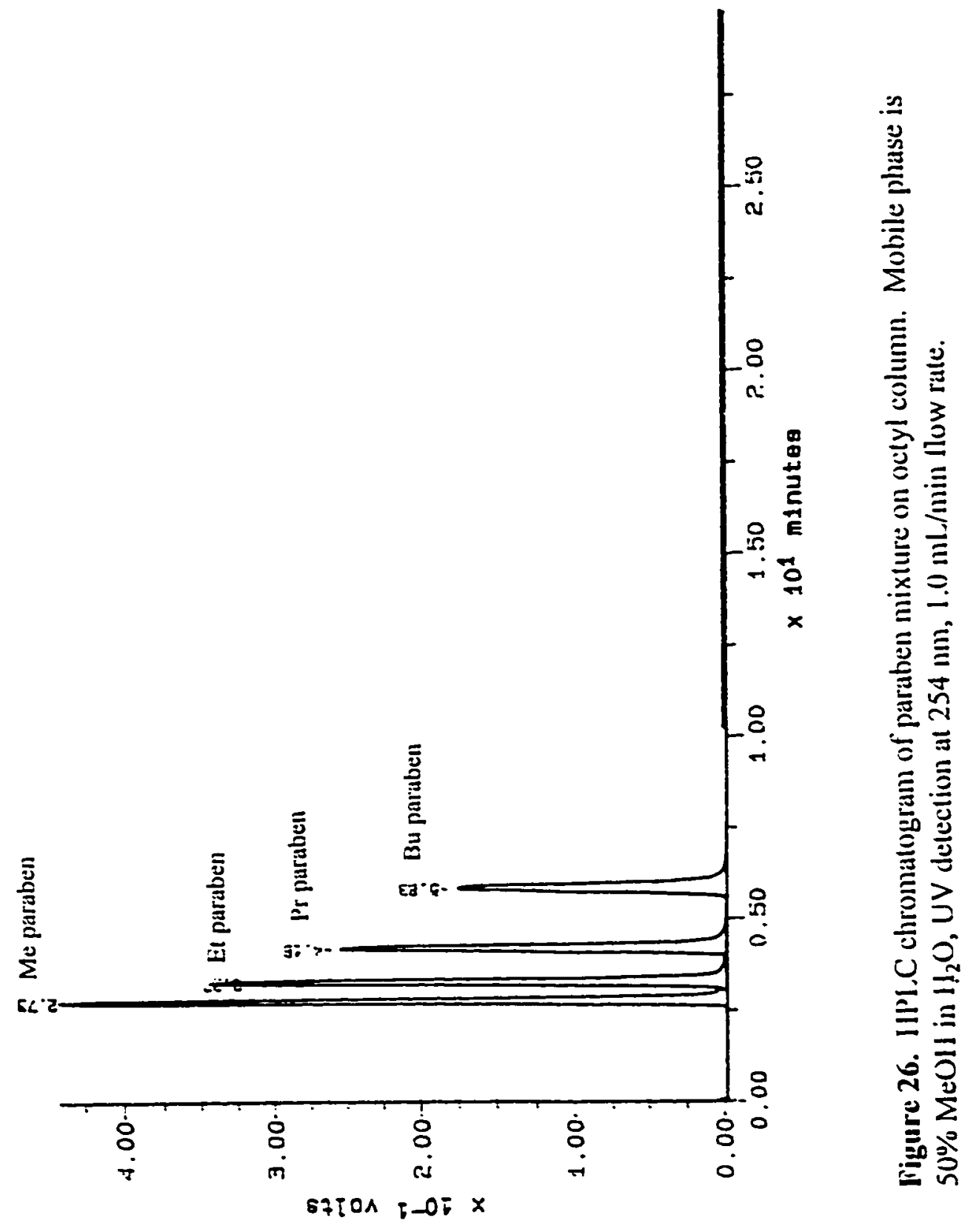




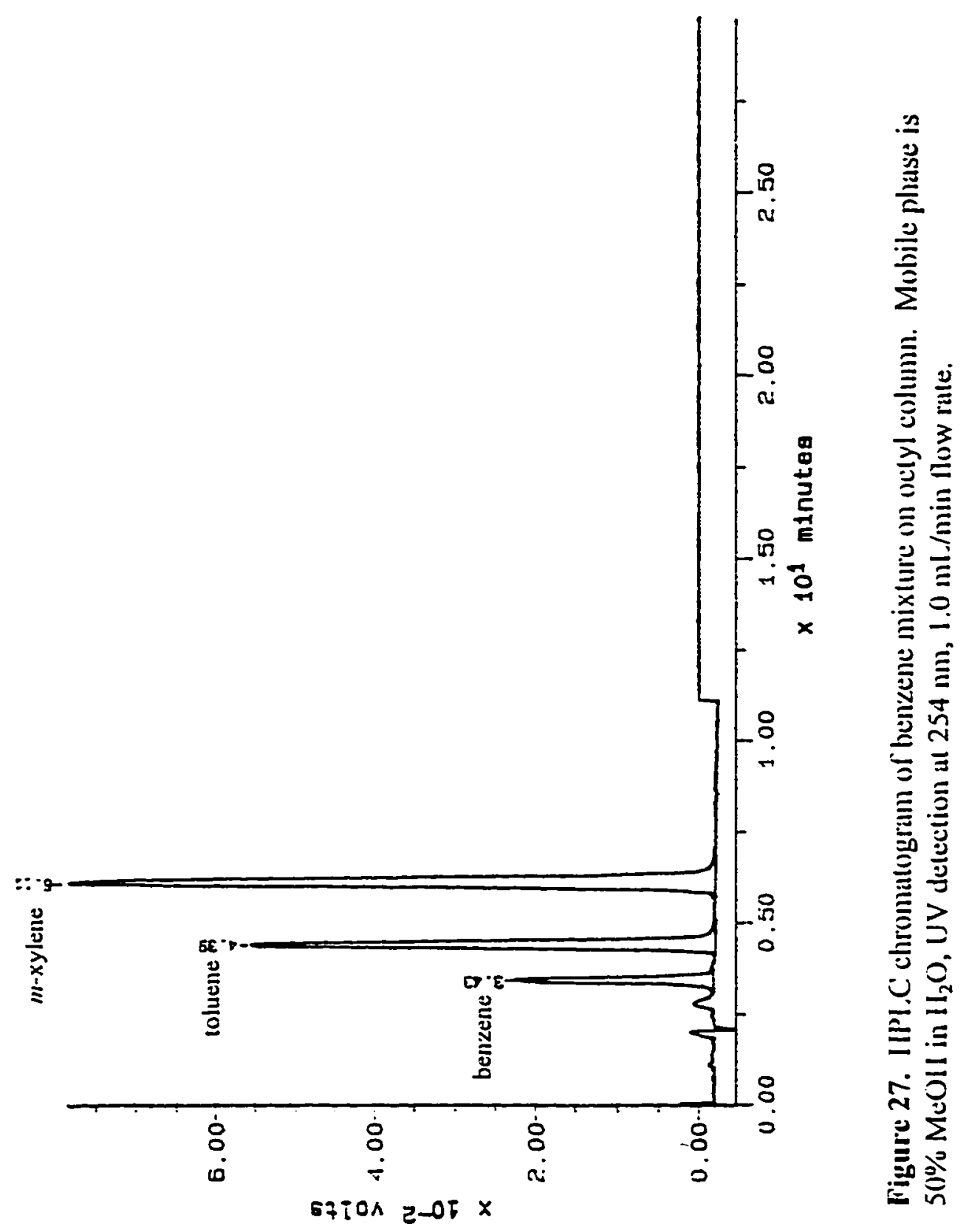




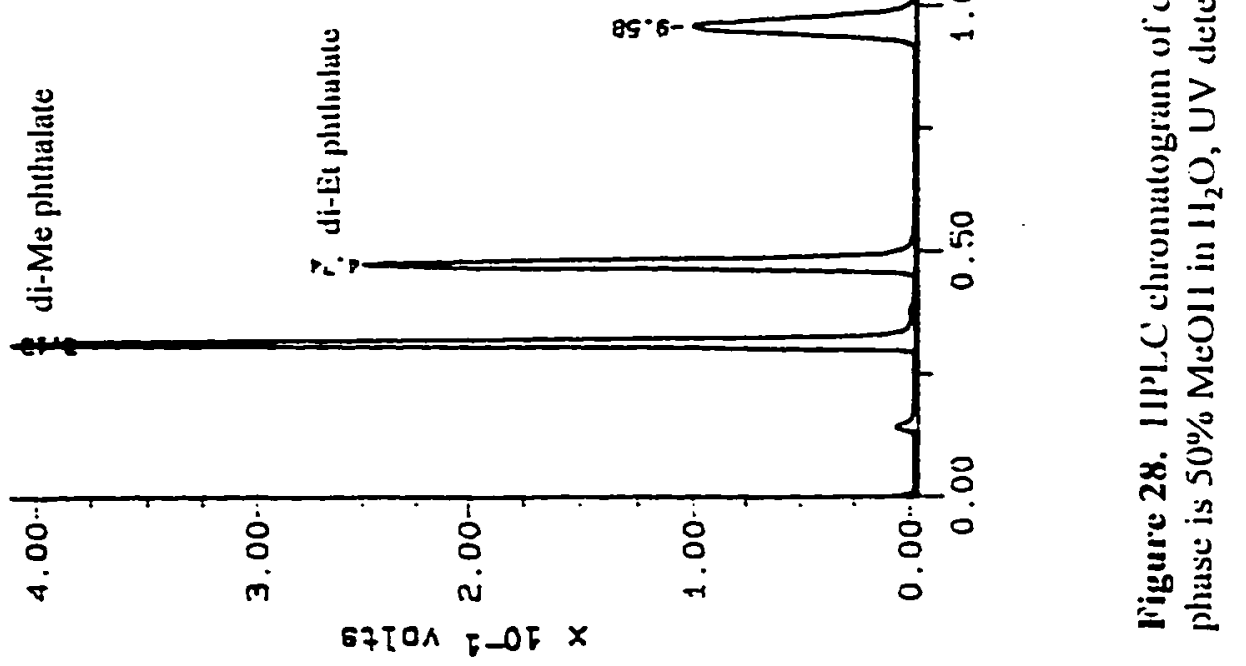




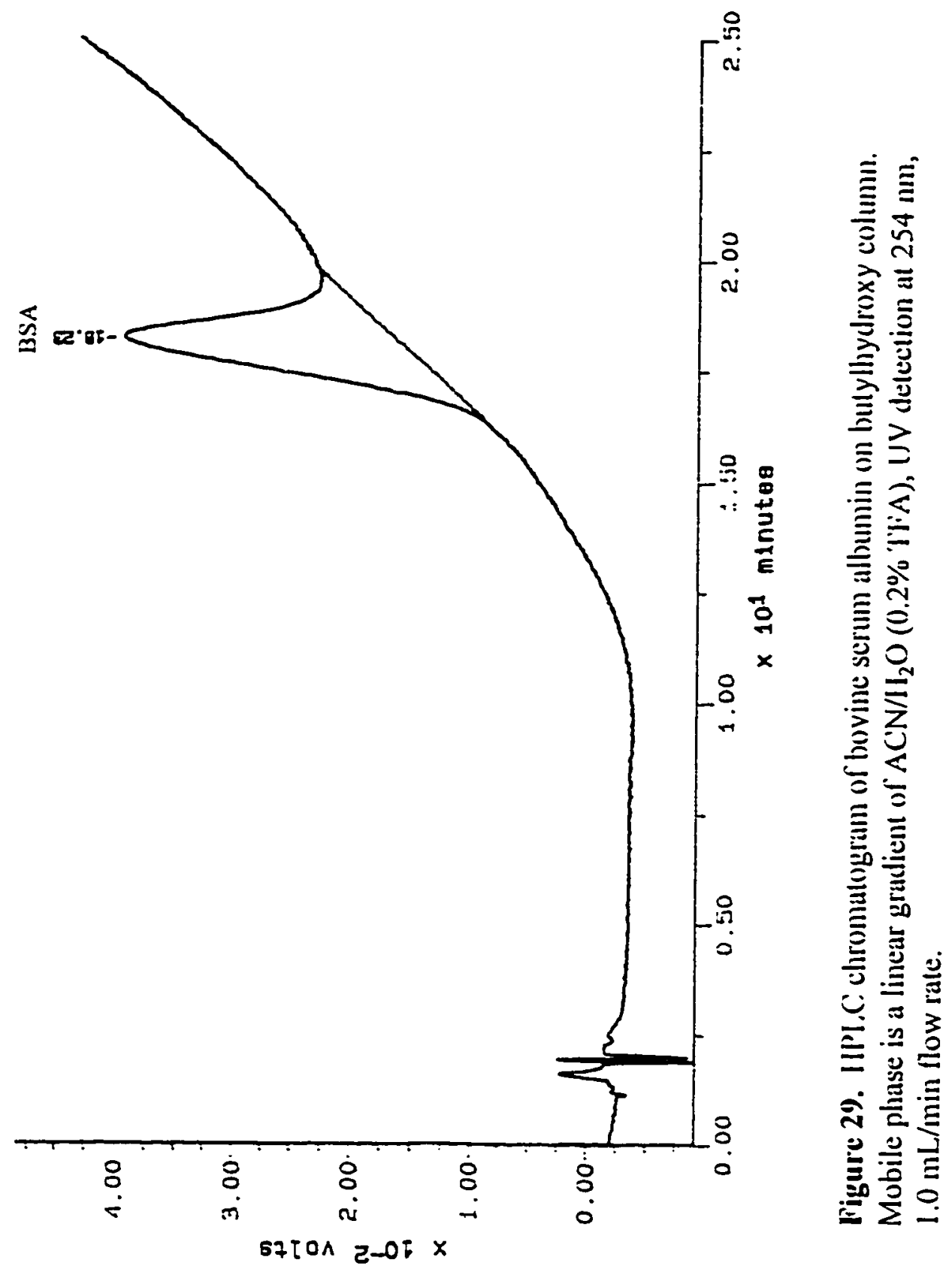




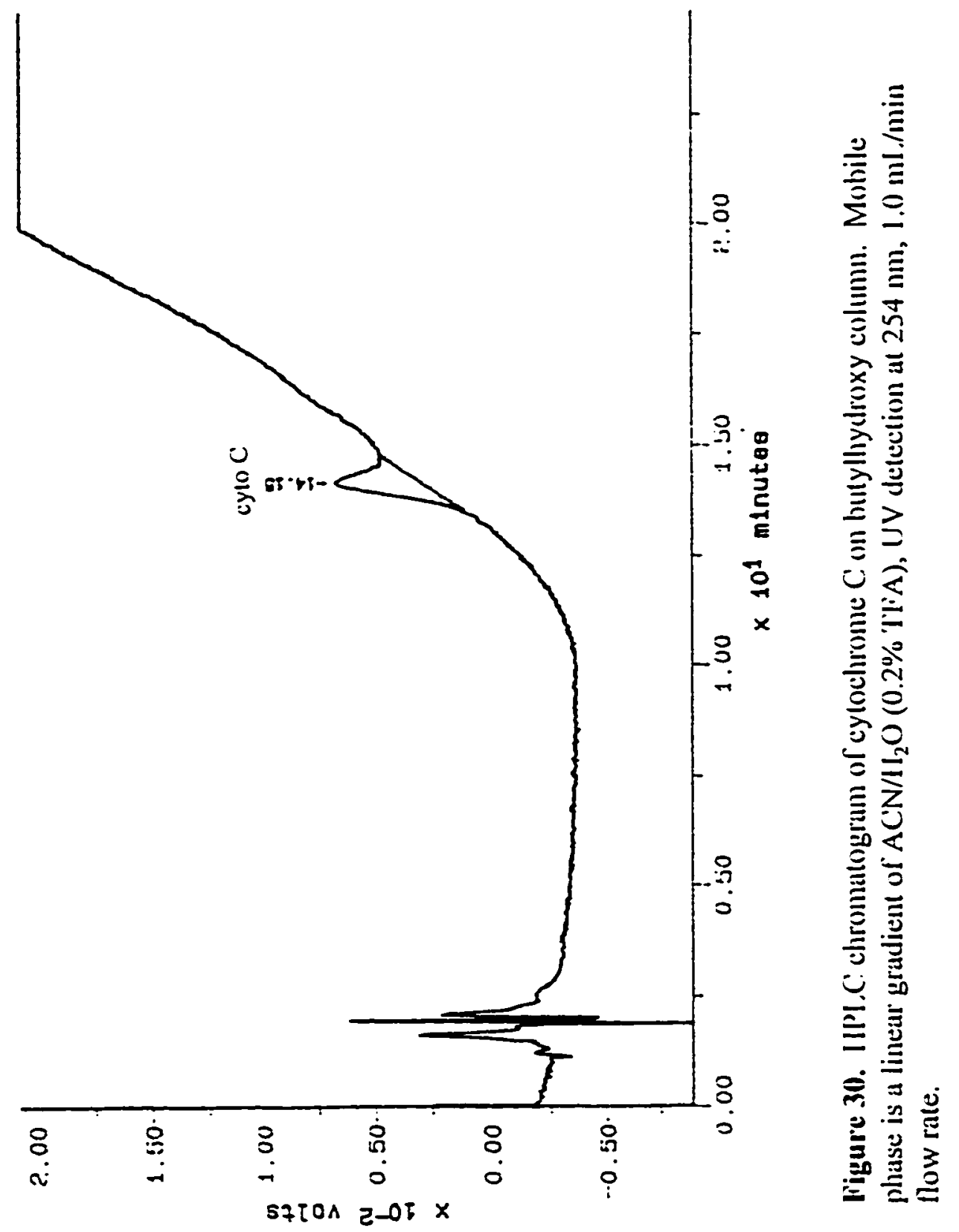




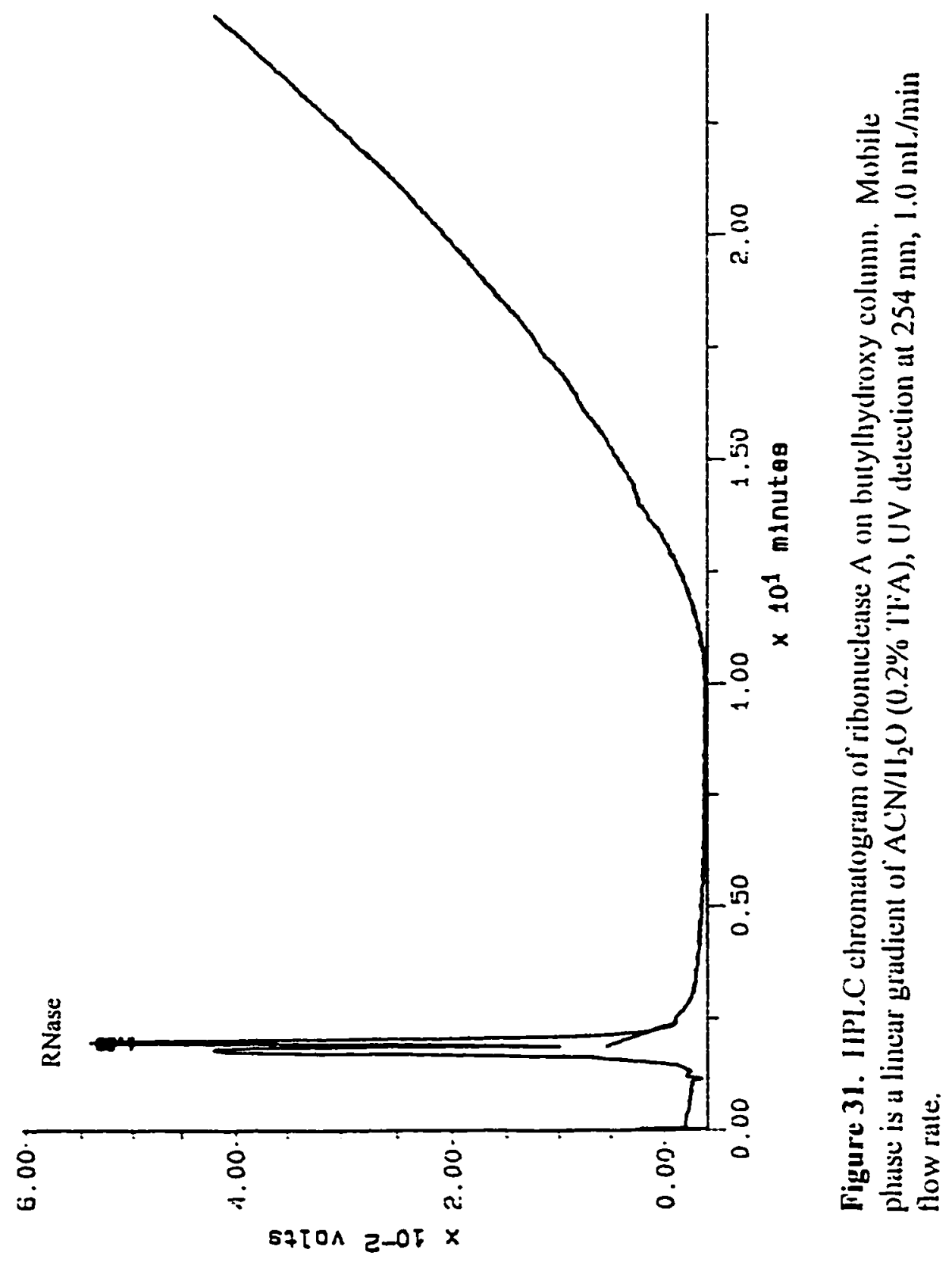




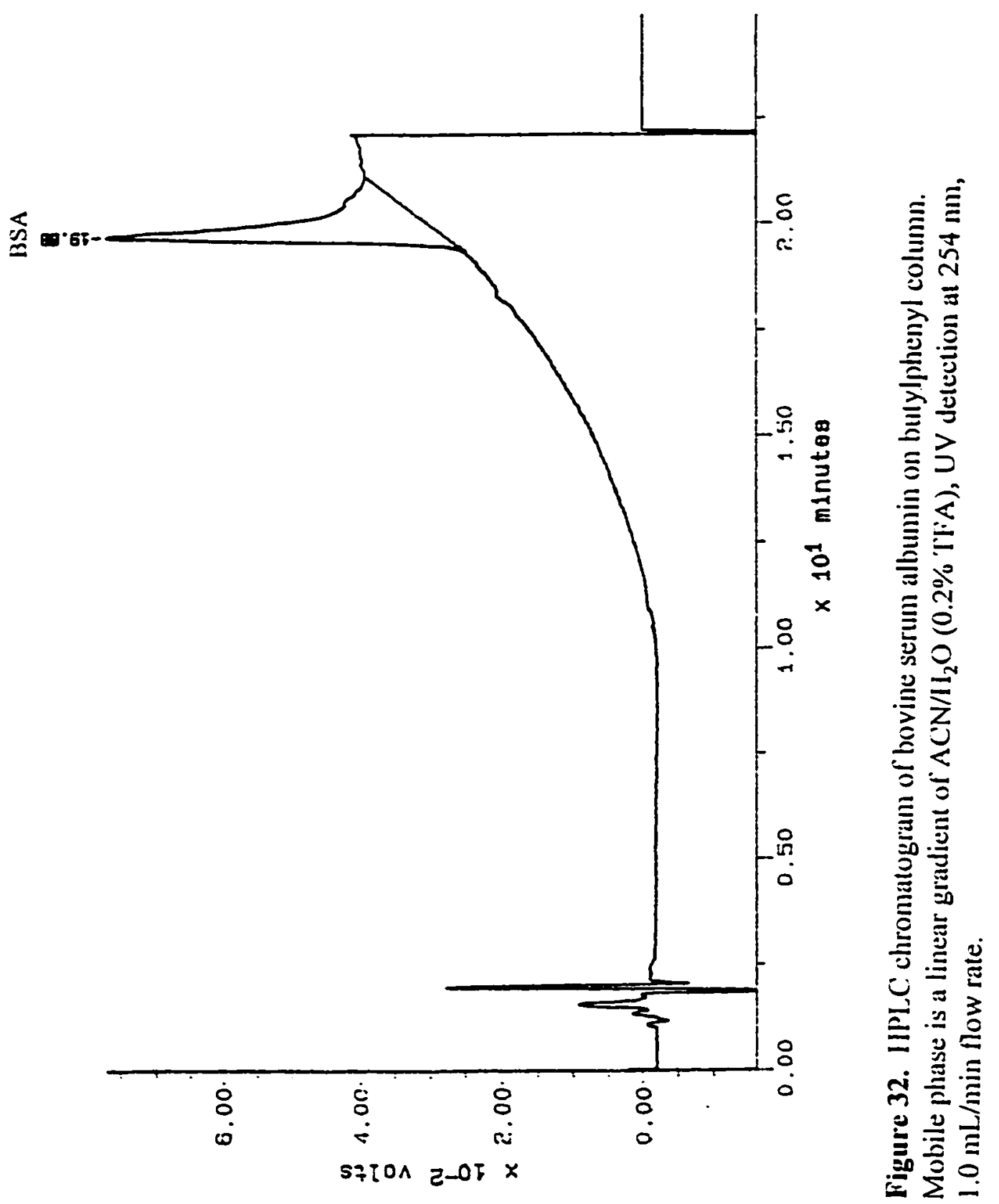




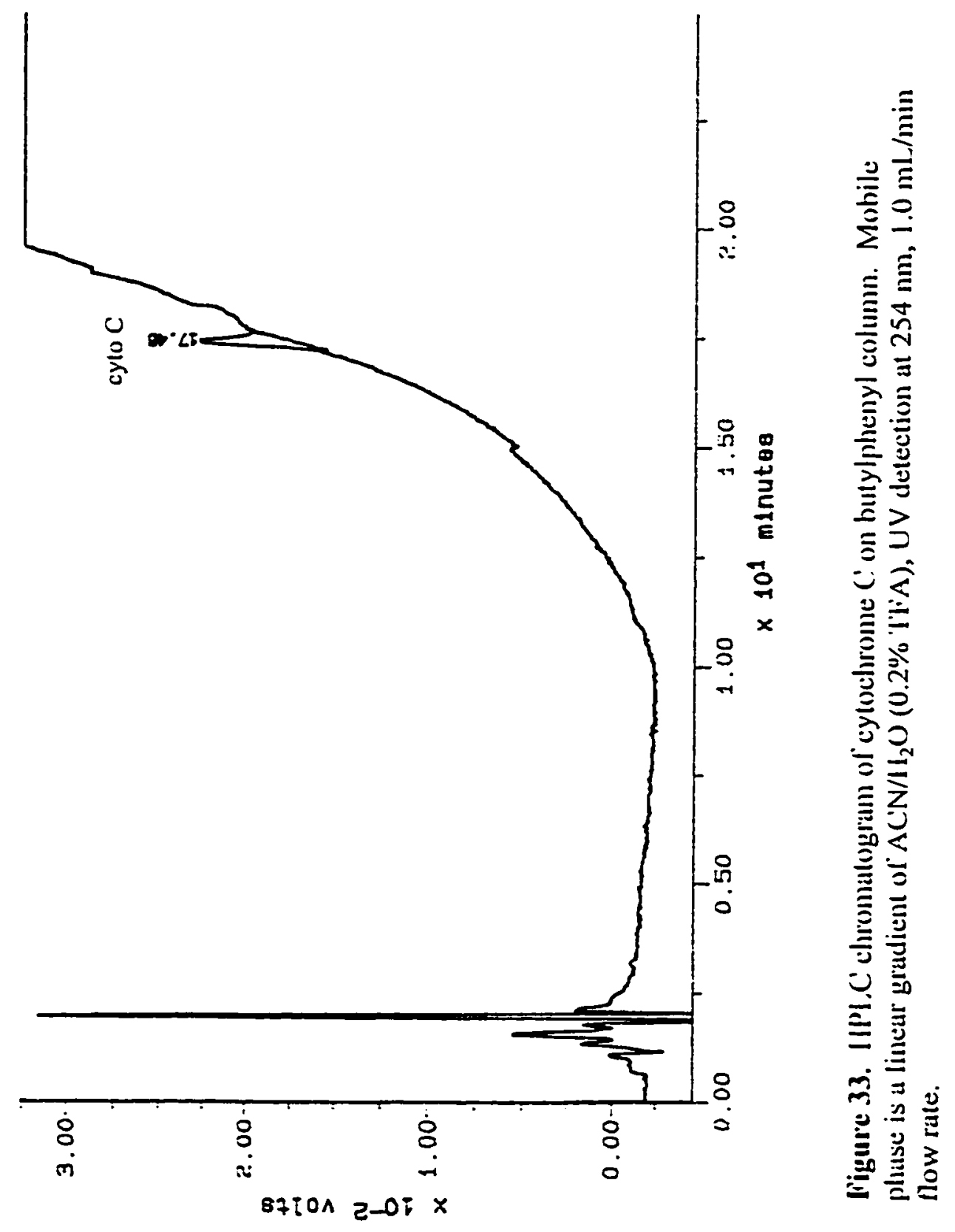




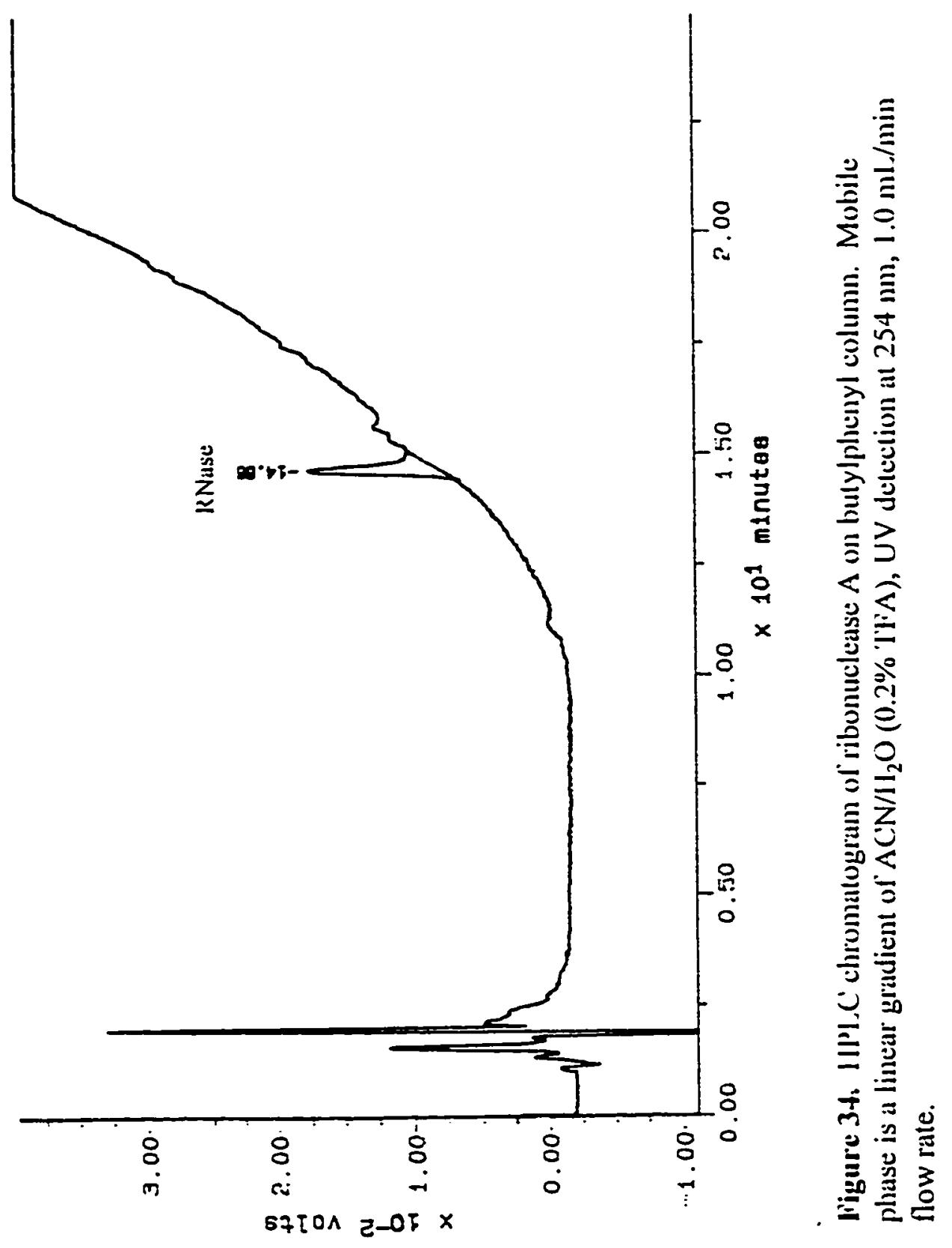




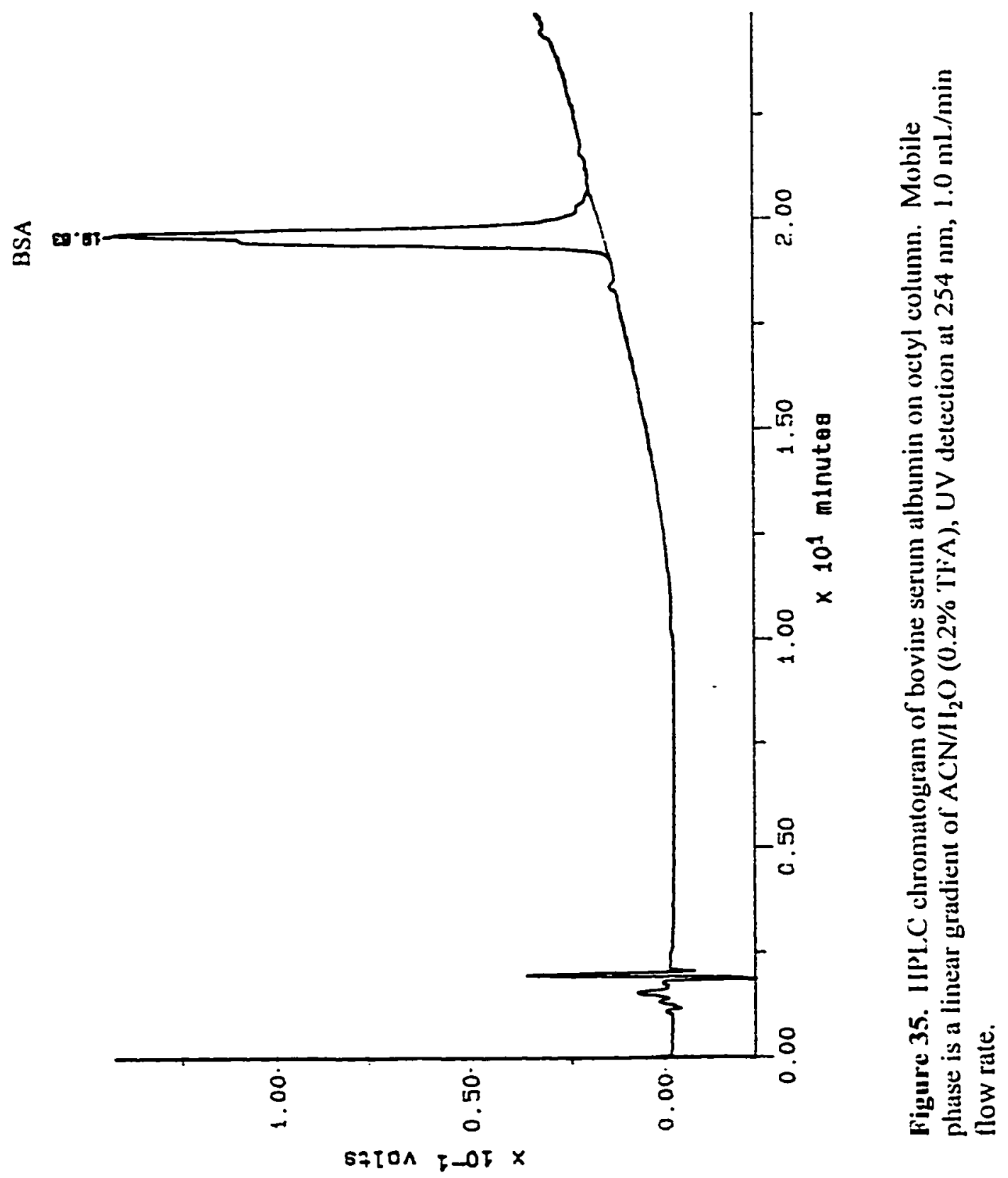




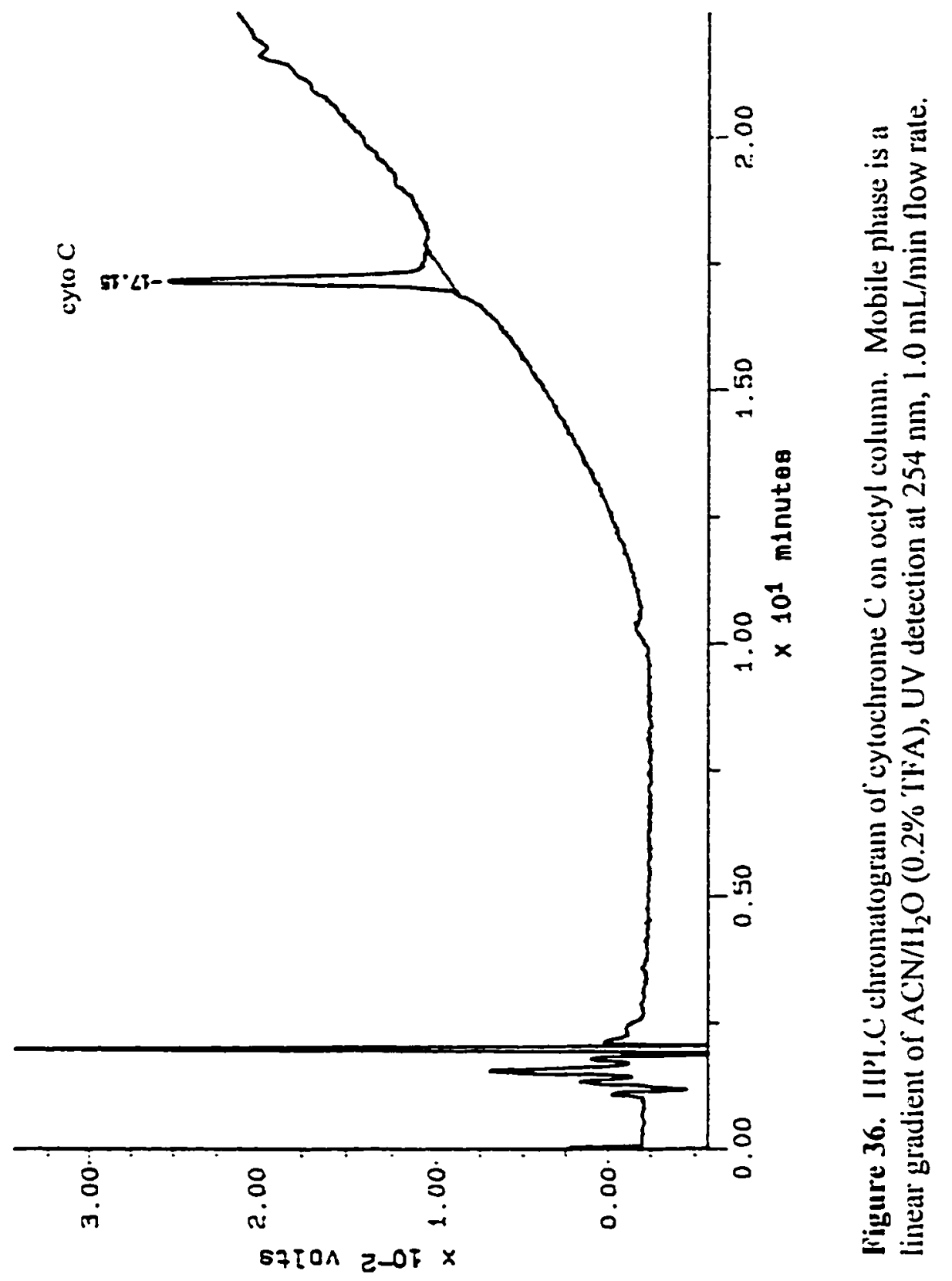




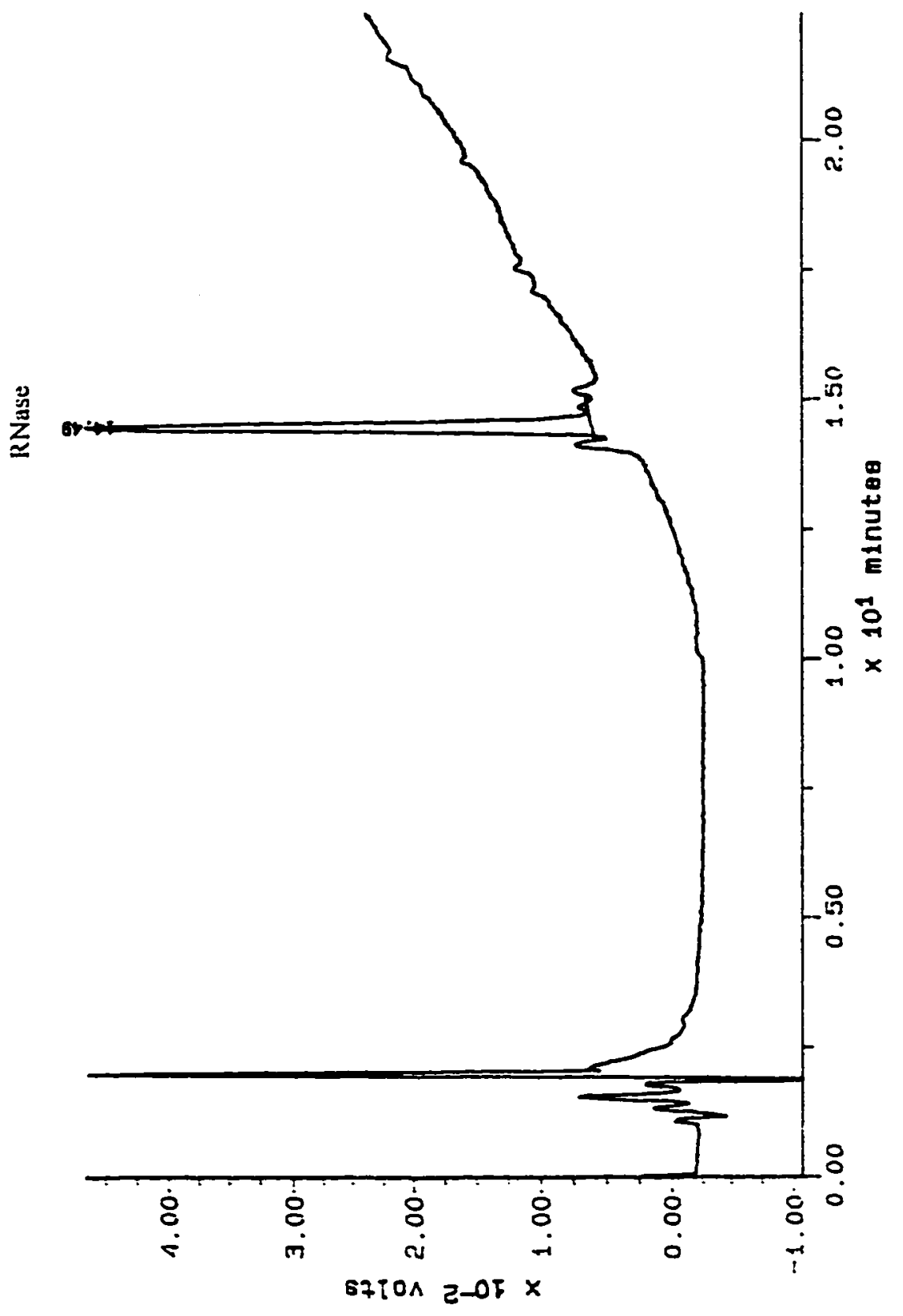

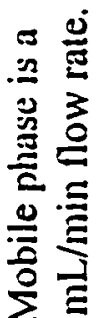

竎总

สก

츨

ธิ ธิํㅡ

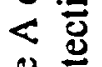

웜

乲引

言

$=$

ํํำ

웅

응

䓂蓄

눙

큼

闩哥

츨

琶 